\title{
MICROZONE EFFECTS IN THE HUTT VALLEY IN RECORDS FROM A STRONG-MOTION ACCELEOGRAPH ARRAY
}

\author{
S. Sritharan1, G. H. McVerry²
}

\begin{abstract}
Ground motions recorded in several earthquakes by the Hutt Valley strong-motion accelerograph array are analyzed to demonstrate an d quantify microzone effects. Spectral amplifications in low to moderate ground shaking are calculated at si tes with different soil conditions with respect to a reference site located on rock adjacent to the edge of the valley. It is shown that the response characteristics of various sites correlate well with the soil conditions uraferlying the sites. A shallow site located on $20 \mathrm{~m}$ of sediment adjacent to the edge of the valley produces short-period amplification, with the average amplification curve for the $5 \%$ damped acceleration response, spectrum peaking at $0.35 \mathrm{~s}$ with a value of 4 . Deeper sites with up to $300 \mathrm{~m}$ of stiff sediments yield brozıd-bancl amplifications up to $2 \mathrm{~s}$ period, with typical maximum amplifications of 5-10. The greatest amplifications, exc eeding 10, are obtainıd at two sites which are located on shallow very soft deposits.
\end{abstract}

\section{INTRODUCTION}

The Engineering S/aismology Section of the Institute of Geological \& Nucle'ar Sciences (formerly part of DSIR) maintains a strong-m.otion accelerograph network for studying microzone effects, in the Hutt Valley and the neighbouring Wainuiomata valley. Since 1966, when the first strong-motion accelerograph rwas installed, there have: been more than 20 earthquakes wi'th $\mathrm{r}$ nagnitude greater than 4 which have triggered the strong-motion instruments in the Hutt Valley. Sets of ground motions recrsrde $d$ on various soil conditions have clearly demonstrate $\mathbb{I}$ the : significance of earthquake microzone effects in the Hutt Val'iey. Various parameters describing the grouncl motion slich as; peak ground acceleration, duration, spectral. amplitudes and frequency content were found to vary markedly across the su' ite of sites, that range from bedrock to thici: alluviu:n to s' oft sediment.

C.onsiderıng; the distribution of geological materials [2] togeth๕: with the jesults from cone and seismic cone penetrometer probing t/sts [10], a microearthquake survey [13] and the strong-motion study discussed in this paper, a microzone map (Fig. 1) consisting of four different seismic ground shaking hazard :zones, namely Zone 1, Zone ?, Zone 3-4 and Z'one 5, was produced for the lower Hutt valley and Wainuiomata. The categories range from Zone 1 which consists of rock at the surface, or with up to $10 \mathrm{~m}$ of deeply weathered gravel on rock, through to Zone 5 which is underlain by more than 201 ) $\mathrm{m}$ (up to $300+\mathrm{m}$ ) depth of gravel with $10-30 \mathrm{~m}$ of soft, flexible sediments at the surface in the lower Hutt valley, or up to 10-

1,2 Institute of Geological \& Nuclear Sciences, P O Box 30-368, Lower Hutt, New Zealand ${ }^{1}$ Member

${ }^{2}$ Fellow
$35 \mathrm{~m}$ of very soft flexible materials underlain by up to $100 \mathrm{~m}$ of gravel in Wainuiomata and Naenae. Full descriptions of the various zones is given in the summary paper published in this bulletin by Van Dissen et. al. [14].

This paper summarises the results of detailed analyses of strongmotion accelerograph records from three rock sites and four soil sites in the Hutt Valley and the quantification of their site characteristics as given in a report completed in May 1991 for the Wellington Regional Council (WRC) [7]. In addition, records from three recently instrumented soil sites where accelerographs have been installed within the last 18 months, are discussed. Two of the recently instrumented sites produced large amplifications in a microearthquake survey reported on by Taber \& Smith [13]. The third new site was located on reclamation land at Seaview to obtain records to better define the nature of the soil amplification in this area. Also, the ground motions recorded in the Hutt Valley in three recent deep events that have occurred following our WRC study are investigated. These deep events, in July 1991, September 1991, and May 1992, give us an opportunity to verify the site characteristics established in the WRC study and to examine the nature of the response of the new sites.

\section{EARTHQUAKES}

Strong-motion records obtained in the Hutt Valley from nine earthquakes are discussed in this paper. Fig. 2 shows the epicentral locations of the earthquakes while Table 1 summarises the source parameters of the events as available in September 1992. 


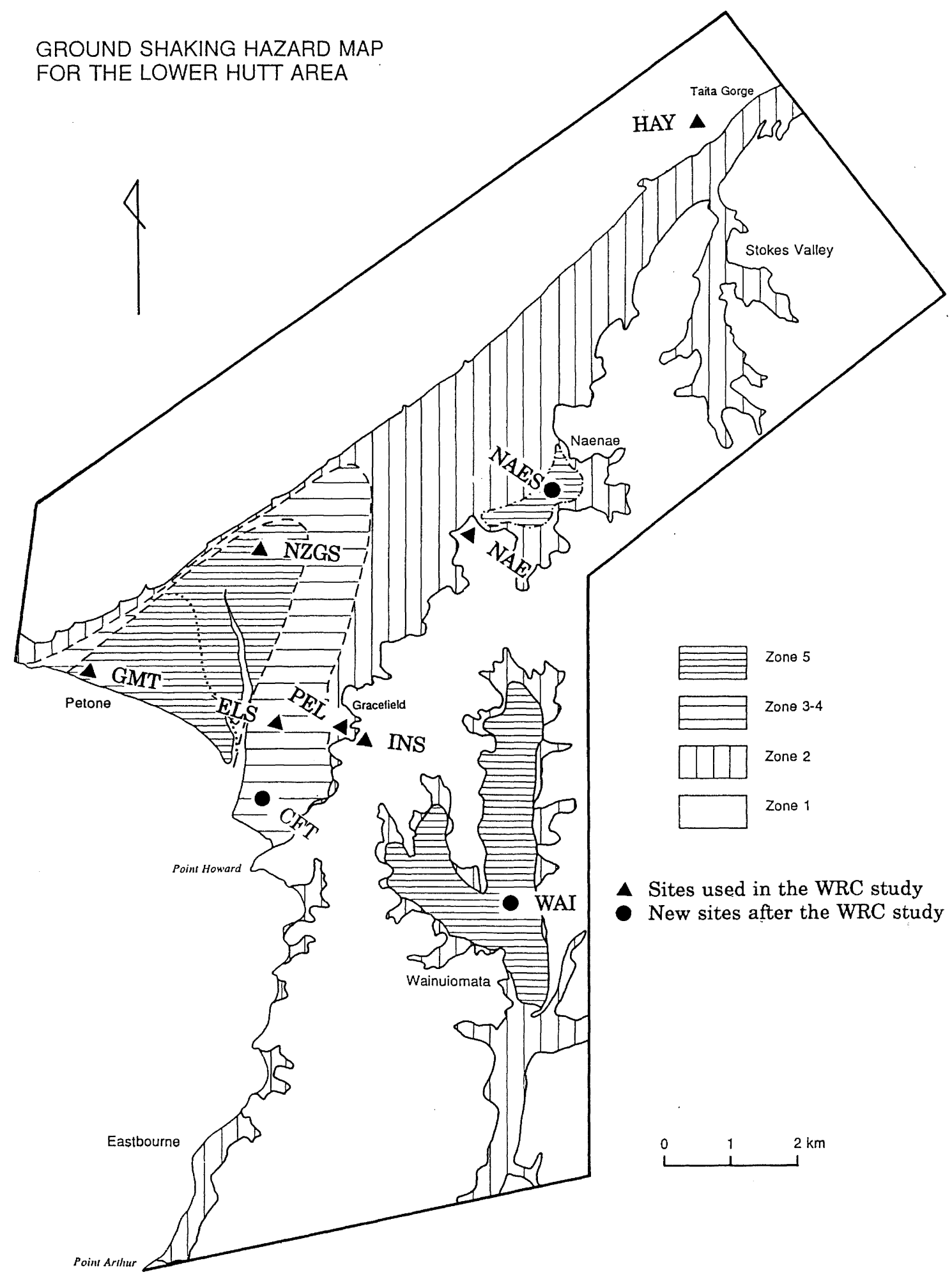

Fig. 1 Microzone map of the Lower Hutt Valley and Wainuiomata and locations of the strong-motion accelerograph sites. Ground conditions vary from Zone 1 (rock) to Zone 5 where strong amplifications may occur. After Fig. 5 of Van Dissen et. al. [14]. 


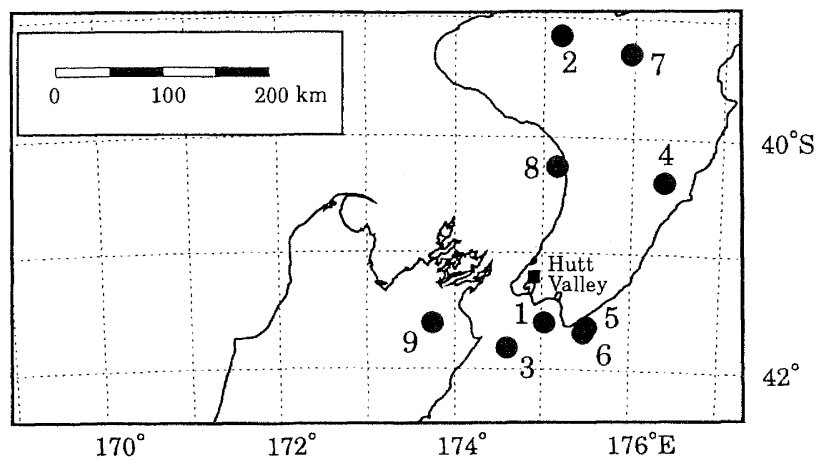

Fig.2

The epicentral locations of the earthquakes discussed in this paper. The event numbers correspond to those given in Table 1.

These events produced contrasting types of ground motions in the Hutt Valley. For example, the strong-motion records from the shallow $M_{L} 6.0$ Cook Strait earthquake in 1977, centred about $70 \mathrm{~km}$ from the Hutt Valley, exhibited relatively strong high-frequency content compared to those from the distant $M_{L}$ 5.9 Weber earthquake in February 1990, and the deep and distant 1973 central North Island $\left(M_{L} 7.0\right)$ event. Motions from moderate to large magnitude $\left(\mathrm{M}_{\mathrm{L}}>5.5-6.0\right)$ distant earthquakes are generally rich in low frequencies, which bring out the longer-period response of the deep alluvial and soft sediment sites.

\section{SITE CONDITIONS AND LOCATIONS}

The Hutt Valley is an elongated sedimentary basin overlying greywacke basement rock. The valley is bounded by moderately steep hills on either side of its major axis. From the mouth of Taita Gorge, it forms a V-shape flat which runs in a south-west direction, with the lower part of the valley open to Port Nicholson (Fig. 1). The Wellington fault lies near the western boundary of the valley. According to the geological map in Dellow et. al. [2], the depth of sediment is about $10-20 \mathrm{~m}$ in the Taita area and increases gradually in the south-west direction along the Wellington fault, reaching over $300 \mathrm{~m}$ in the Petone foreshore area. The major axis of the valley has been taken as $\mathrm{N} 54 \mathrm{E}$, with the cross-valley direction taken as N36W.

Of the ten accelerograph sites considered in this paper, three are sited part way up the surrounding hills in Zone 1 (rock near the surface) and the remaining seven are located on sediments of various depths in Zone 2 to Zone 5. Two of the Zone 1 rock sites, INS and HAY, are on flat excavated terraces about $30 \mathrm{~m}$ and $60 \mathrm{~m}$ above the valley floor at Gracefield and at Haywards respectively. The third rock site, NAE, is on a ridge at Naenae about $90 \mathrm{~m}$ above the valley floor. The PEL site is located adjacent to the edge of the valley, about $400 \mathrm{~m}$ from INS, in Zone 2 , on $20 \mathrm{~m}$ of sediments composed of $12 \mathrm{~m}$ of loosemedium dense gravel and soft-firm silt over $8 \mathrm{~m}$ of medium dense sand, silt, and gravel. Zone 3-4 contains two strongmotion accelerograph sites, one at Elizabeth Street, ELS, and the other on reclamation land at Seaview, CFT. The ELS and CFT sites are underlain by about $200 \mathrm{~m}$ and $150 \mathrm{~m}$ alluvium respectively, with $20 \mathrm{~m}$ of soft deposits at each site overlying the very dense gravels. There are four sites in Zone 5, two with deep sediments underlying soft material and the other two on softer but shallower sediments. The former Gear Meat site, GMT, is located near the deepest part of the valley on about 300 $\mathrm{m}$ of sediments, with up to $30 \mathrm{~m}$ depth of soft materials (shear wave velocity of about $175 \mathrm{~m} / \mathrm{s}$ [14]) at the surface. GMT is immediately adjacent to the Wellington fault where there is a large buried scarp in the bedrock surface, about $750 \mathrm{~m}$ from the

Table 1: The descriptions of the earthquakes used in this paper as available in September 1992.

\begin{tabular}{||l|l|c|c|c|c|c|c|c||}
\hline \multicolumn{1}{|c|}{ Earthquake } & $\begin{array}{c}\text { Date } \\
(\mathbf{D} / \mathbf{M} / \mathbf{Y})\end{array}$ & $\begin{array}{c}\text { Time } \\
(\mathbf{U T})\end{array}$ & Lat. & Long. & $\mathbf{M}_{\mathbf{L}}$ & $\begin{array}{c}\text { Depth } \\
\text { (km) }\end{array}$ & $\begin{array}{c}\text { Epicentral } \\
\text { distance } \\
\text { from INS* } \\
\text { (km) }\end{array}$ \\
\hline 1 & Palliser Bay & $01 / 11 / 68$ & $01: 32$ & $41.62 \mathrm{~S}$ & $175.05 \mathrm{E}$ & 5.4 & $33 \mathrm{R}$ & 40 \\
2 & Central North Island & $05 / 01 / 73$ & $13: 54$ & $39.13 \mathrm{~S}$ & $175.18 \mathrm{E}$ & 7.0 & 173 & 240 \\
3 & Cook Strait & $18 / 01 / 77$ & $05: 42$ & $41.84 \mathrm{~S}$ & $174.58 \mathrm{E}$ & 6.0 & 33 & 70 \\
4 & Weber (February) & $19 / 02 / 90$ & $05: 34$ & $40.36 \mathrm{~S}$ & $176.36 \mathrm{E}$ & 5.9 & 24 & 150 \\
5 & Cape Palliser (Event 1) & $04 / 10 / 90$ & $23: 48$ & $41.64 \mathrm{~S}$ & $175.51 \mathrm{E}$ & 4.9 & 23 & 70 \\
6 & Cape Palliser (Event 2) & $06 / 10 / 90$ & $02: 41$ & $41.69 \mathrm{~S}$ & $175.50 \mathrm{E}$ & 5.0 & 22 & 70 \\
7 & Unnamed (under Taupo) & $12 / 07 / 91$ & $04: 42$ & $39.30 \mathrm{~S}$ & $175.98 \mathrm{E}$ & 6.4 & 71 & 230 \\
9 & Unnamed (Offshore from Bulls) & $08 / 09 / 91$ & $13: 51$ & $40.25 \mathrm{~S}$ & $175.16 \mathrm{E}$ & 6.3 & 87 & 110 \\
\hline
\end{tabular}

* INS is located in the southern lower Hutt Valley (see Fig. 1) 
western boundary of the valley. The site designated NZGS is located on the edge of the central business district of Lower Hutt on $275 \mathrm{~m}$ deep alluvium. There is possibly either a peat layer or a very loose saturated sand filled channel in the top 10 $\mathrm{m}$ [6]. The two very soft sites are located at Naenae on a possible former swamp area, NAES, and at Wainuiomata, WAI. The flexible sediment conditions at the NAES site were revealed in the course of the WRC study from cone penetrometer testing, and the seismic response of this area. Depth to bedrock at this site is estimated at $50 \mathrm{~m}$, with about $10 \mathrm{~m}$ of soft deposits overlying dense gravel. WAI comprises $30 \mathrm{~m}$ of very soft deposits (shear wave velocity of $90 \mathrm{~m} / \mathrm{s}$ for the top $20 \mathrm{~m}$ [10]) and $20 \mathrm{~m}$ of soft to firm alluvial sand, silt and clay over $12 \mathrm{~m}$ of very stiff weathered gravel, sand and clay, with bedrock at $62 \mathrm{~m}$. Three of the soil sites (PEL, ELS and GMT) and the INS rock site are almost aligned across the lower part of the valley (Fig. 1), allowing the variation in the response characteristics across the valley to be examined.

Table 2 provides the soil conditions at each site in detail, while the peak horizontal ground accelerations obtained in each event are listed in Table 3.

\section{METHOD}

The accelerograms were processed using the standard techniques of the New Zealand strong-motion programme [1]. The horizontal components of each accelerogram were rotated to the N54E and N36W directions, the nominal along-valley and cross- valley directions. Appropriate filter bands were selected to diminish the effects of noise and base-line shift on the true signal, and the Fourier amplitude spectrum of the acceleration and the $5 \%$ damped acceleration response spectrum were then calculated for each horizontal component of the records.

Transfer functions were used to characterise the differences between the records from the various sites and a reference rock site. The analyses were carried out for both the Fourier spectra of acceleration and the $5 \%$ damped acceleration response spectra of the records. Results are presented in this paper mainly for the latter analysis because the damping smooths the amplification spectra, making them easier to interpret than the Fourier spectral ratios which are often erratic despite applying Hanning smoothing to the input and output signals, and to the ratio. The Fourier spectra were useful in that they were generally calculated with better frequency resolution than the response spectra, particularly at low frequencies (long periods), and because the Fourier spectrum of acceleration is closely related to the undamped velocity response spectrum long-period peaks were more prominent than in the acceleration response spectra. Note that care was taken to ensure that the accelerograms forming the input and output signals to each transfer function were filtered with the same frequency bands.

Table 2: Locations of the strong-motion accelerographs and descriptions of the site conditions as given by Perrin [6].

\begin{tabular}{|c|c|c|c|c|}
\hline Site ID & Location & $\begin{array}{l}\text { Zone } \\
\text { type }\end{array}$ & $\begin{array}{c}\text { Depth to } \\
\text { Bedrock (m) }\end{array}$ & Description \\
\hline INS & $\begin{array}{l}\text { INS, Gracefield (floor of a } 2 \text { storey (equiv.) } \\
\text { steel frame bldg) }\end{array}$ & 1 & 0 & $\begin{array}{l}\text { Highly-weathered greywacke bedrock, weak, but strength increases with } \\
\text { depth }\end{array}$ \\
\hline HAY & $\begin{array}{l}\text { Haywards Substation (floor of a } 2 \mathrm{~m} \text { deep } \\
\text { concrete services tunnel) }\end{array}$ & 1 & $0-8$ & $\begin{array}{l}\text { Fine-grained, cohesive fill and stiff clay (completely weathered gravel) over } \\
\text { weak, completely weathered bedrock at }<8 \mathrm{~m} \text { depth (essentially a stiff site) }\end{array}$ \\
\hline NAE & $\begin{array}{l}\text { Naenae ( } 8 \mathrm{~m} \text { below surface on the basement of } \\
\text { a water storage reservoir) }\end{array}$ & 1 & 0 & $\begin{array}{l}\text { Completely-weathered greywacke bedrock, weak but strength increases } \\
\text { rapidly with depth }\end{array}$ \\
\hline PEL & $\begin{array}{l}\text { PEL, Gracefield (floor of concrete tunnel } \\
\text { beneath a } 2 \text { storey reinforced concrete bldg) }\end{array}$ & 2 & 20 & $\begin{array}{l}12 \mathrm{~m} \text { of loose-medium dense gravel and soft-firm silt and } 8 \mathrm{~m} \text { of medium } \\
\text { dense sand, silt and gravel }\end{array}$ \\
\hline ELS & $\begin{array}{l}\text { Elizabeth Street, Moera (floor of a } 2 \text { storey } \\
\text { (equiv.) reinforced concrete bldg) }\end{array}$ & $3-4$ & 200 & $\begin{array}{l}20 \mathrm{~m} \text { of soft/loose silt and sandy gravel, } 30 \mathrm{~m} \text { of compact sandy gravel, } 15- \\
20 \mathrm{~m} \text { stiff sandy silt/clay and } 130 \mathrm{~m} \text { very dense gravel }\end{array}$ \\
\hline CFT & $\begin{array}{l}\text { Croft Combined Carriers, Seaview (floor of a } \\
2 \text { storey (equiv.) steel frame bldg) }\end{array}$ & $3-4$ & 150 & $\begin{array}{l}4 ? \mathrm{~m} \text { fill, } 16 \mathrm{~m} \text { of soft/loose sandy gravel and silt, } 25 \mathrm{~m} \text { medium dense } \\
\text { gravel, } 15 \mathrm{~m} \text { stiff sandy silt/clay and } 90 \mathrm{~m} \text { very dense sandy gravel }\end{array}$ \\
\hline GMT & $\begin{array}{l}\text { Gear Meatworks, Petone (floor of a single } \\
\text { storey small concrete bldg) }\end{array}$ & 5 & 298 & $\begin{array}{l}30 \mathrm{~m} \text { loose sand, sandy gravel and silty sand and soft sandy silt, } 60 \mathrm{~m} \text { dense } \\
\text { gravel, } 20 \mathrm{~m} \text { stiff sandy silt/clay and } 190 \mathrm{~m} \text { very dense gravel }\end{array}$ \\
\hline NZGS & $\begin{array}{l}\text { Geological Survey, Lower Hutt (floor of } \\
\text { concrete garage under a } 2 \text { storey timber house) }\end{array}$ & 5 & 275 & $\begin{array}{l}10 \mathrm{~m} \text { soft to firm clay/silt and loose sandy gravel, } 40 \mathrm{~m} \text { medium dense to } \\
\text { dense gravel and } 225 \mathrm{~m} \text { of very dense gravel. }\end{array}$ \\
\hline NAES & $\begin{array}{l}\text { Naenae Substation (floor of a single storey } \\
\text { brick bldg) }\end{array}$ & 5 & 50 & $\begin{array}{l}10 \mathrm{~m} \text { fill and very soft clay/silt (swamp sediment?), } 40 \mathrm{~m} \text { medium dense to } \\
\text { dense gravel }\end{array}$ \\
\hline WAI & $\begin{array}{l}\text { Wainuiomata Fire Station (floor of a single } \\
\text { storey light weight garage) }\end{array}$ & 5 & 62 & $\begin{array}{l}<1 \mathrm{~m} \text { soft to firm clay/silt, } 30 \mathrm{~m} \text { very soft silt/clay, } 5 \mathrm{~m} \text { firm gravelly silt, } 6 \\
\mathrm{~m} \text { firm clay and medium dense sand, } 8 \mathrm{~m} \text { stiff sandy silt, dense silty sand, } \\
\text { and } 12 \mathrm{~m} \text { very stiff sandy silt/clay and dense gravel }\end{array}$ \\
\hline
\end{tabular}


Table 3: Peak horizontal accelerations in 'g' obtained at various sites in the events given in Table 1.

\begin{tabular}{||c|c|c|c|c|c|c|c|c|c||}
\cline { 2 - 9 } \multicolumn{1}{c|}{} & \multicolumn{8}{c||}{ Dates of Earthquakes } \\
\hline \hline SIDE ID & $\mathbf{0 2 / 1 1 / 6}$ & $\mathbf{0 5 / 0 1 / 7}$ & $\mathbf{1 8 / 0 1 / 7 7}$ & $\mathbf{1 9 / 0 2 / 9 0}$ & $\mathbf{0 4 / 1 0 / 9 0}$ & $\mathbf{0 6 / 1 0 / 9 0}$ & $\mathbf{1 2 / 0 7 / 9 1}$ & $\mathbf{0 8 / 0 9 / 9}$ & $\mathbf{2 6 / 0 6 / 9 2}$ \\
& $\mathbf{8}$ & $\mathbf{3}$ & & & & & & $\mathbf{1}$ & \\
\hline INS & 0.095 & 0.026 & 0.071 & 0.005 & 0.017 & 0.013 & - & 0.020 & 0.014 \\
HAY & 0.119 & 0.071 & - & - & - & - & - & - & - \\
NAE & - & - & 0.036 & - & - & - & - & - & - \\
PEL & 0.127 & 0.059 & 0.097 & 0.015 & 0.041 & 0.030 & 0.003 & 0.060 & 0.043 \\
ELS & - & 0.059 & 0.073 & - & 0.042 & - & - & - & 0.028 \\
CFT & - & - & - & - & - & - & - & 0.028 & 0.031 \\
GMT & - & 0.030 & 0.055 & - & - & - & - & - & - \\
NZGS & - & - & - & 0.013 & 0.037 & 0.021 & 0.006 & 0.050 & 0.021 \\
NAES & - & - & - & - & - & - & 0.008 & 0.056 & 0.035 \\
WAI & - & - & - & - & - & - & 0.006 & 0.055 & 0.032 \\
\hline
\end{tabular}

The ground motions recorded at INS were used as the reference motions in this study. Initially, the characteristics of the INS site were derived from the records obtained in the 1968, 1973 and 1977 earthquakes (Table 1). The site spectra calculated from these three records showed consistent character, producing velocity spectra corresponding to a typical hard rock site with short-period peaks and nearly constant amplitudes for long periods, in contrast to the spectra from the other Hutt Valley rock sites which appeared to be affected by site specific characteristics. A more sensitive digital accelerograph has been deployed at INS since April 1989 in addition to the original MO (mechanical-optical) accelerograph, and so rock motions corresponding to more than 15 events are now available from this site.

A mean log acceleration response spectrum shape (ie. spectrum normalised by the peak ground acceleration) was calculated for INS during the WRC study using the two orthogonal components from 13 earthquakes. The magnitudes of these events range from $M_{L} 4.0$ to $M_{L} 7.0$ with epicentral distances ranging from about $10 \mathrm{~km}$ to $240 \mathrm{~km}$, with an average local magnitude of 5.4 and an average epicentral distance of $90 \mathrm{~km}$ from INS. Fig 3 shows the mean log spectral shape and \pm one standard deviation calculated for INS, and the spectral shape derived for Ground Class I (rock) from the spectral shape given in the New Zealand draft loading code 1989 [9], which is based on uniform hazard spectra derived using a modified version [4] of the Katayama response spectrum model [3]. The draft code recommends the spectral shape for Katayama's Ground Class (GC) III, described as alluvial layer with depth less than $25 \mathrm{~m}$. We determined the GC I spectral shape from the GC III code spectrum using the ratio of Katayama's GC I factor to GC III factor for each period up to $1.0 \mathrm{~s}$, with a constant velocity spectrum for periods greater than $1.0 \mathrm{~s}$. A good agreement between the two spectral shapes is seen up to about $0.5 \mathrm{~s}$, but as the period becomes longer the DZ4203 curve shows increasingly greater values than the INS mean log spectral shape. This is not unexpected given that the average magnitude of 5.4 suggests that the mean spectral shape calculated for INS represents an event of small to moderate magnitude. Larger magnitude events produce relatively strong long-period motions, so the spectral shape for INS in a large magnitude event may be nearer to that of the DZ4203 rock spectrum.

For calculating the transfer functions, the soil site motions and the driving rock motions are considered in the same directions, consistent with simple one-dimensional shear-beam theory. As an alternative, Stephenson $[11,12]$ reported the possibility of existence of "cellular mode excitation" in the Hutt Valley. In his cellular mode hypothesis, the transverse component at the rock site with respect to the source should be considered as the motion driving the resonant component at the soil site. Several pairs of strong-motion records obtained from the reference site and the nearby PEL soil site, which were sites used by Stephenson to describe his hypothesis, were reanalysed in our WRC study [7]. We found that the alternative choices of input components produced no marked differences in the results, and the shear-beam approach was considered satisfactory for the purposes of our study. The PEL site did, however, show marked directionality in its response to most earthquakes, with the along-valley component usually being considerably stronger than the cross-valley component for this site close to the edge of the valley.

\section{EXAMPLES OF MICROZONE EFFECTS}

Sets of records obtained from the 1973 and 1990 Cape Palliser (Event 1) earthquakes are discussed in this section to illustrate the microzone effects observed in the Hutt Valley.

Twenty-second segments of the acceleration histories from the $S$ - wave motions obtained in the along-valley (N54E) direction at four sites in the distant, deep, $\mathrm{M}_{\mathrm{L}} 7.0$ central North Island event of 1973 and the corresponding velocity plots are shown in Fig. 4. As expected, the INS rock site acceleration contains high-frequency motion. Its maximum acceleration is smaller than at PEL and ELS. Although the acceleration history of ELS resembles that of PEL for the first few seconds, lower- 
frequency motion, presumably an effect of greater thickness of the sediments, influences the later part of the record at ELS. The difference in the low-frequency content of the ground shaking at these two sites shows up clearly in the velocity plots. At GMT, the site with deepest sediment, the high frequencies are attenuated considerably and the ground motion is dominated by low-frequency cycles. Again, the longer-period response is conspicuous in the velocity plot.
The GMT acceleration history appears to be incomplete. The MO2 type accelerograph that was in operation at the site is triggered by vertical ground motion and runs for 40-50 s. Unfortunately, the run ended during the strong part of the horizontal motion, and this suggests that the spectral amplitudes corresponding to the actual motion may be slightly larger than those calculated for the recorded motion, particularly at long periods.

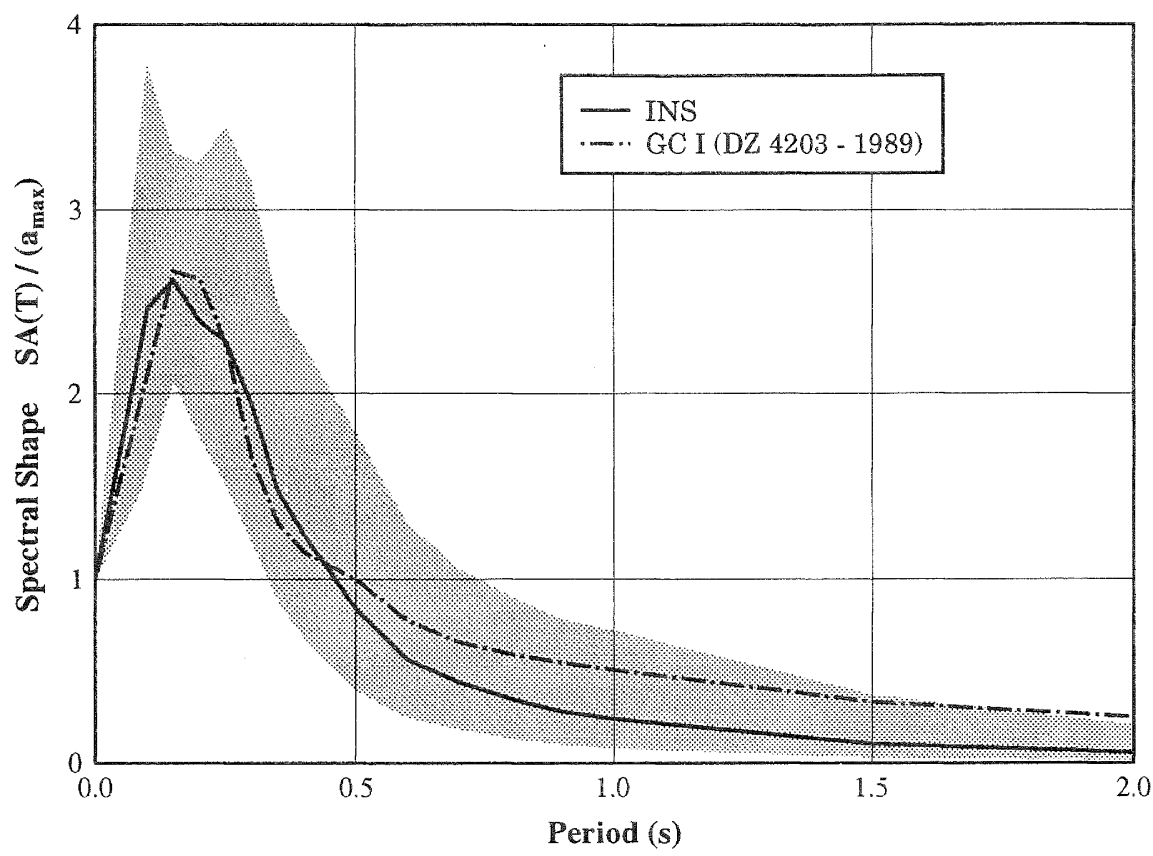

Fig. 3 The mean $\log 5 \%$ damped acceleration response spectrum shape for the reference INS rock site and the corresponding \pm one standard deviation (shaded band), and the GC 1 (rock) spectral shape derived from the DZ4203 draft code. See Fig. 1 for site location

Fig. 5 shows the $5 \%$ damped velocity response spectra in the cross-valley (N36W) direction for the four sites in the same event. As indicated by McVerry \& Sritharan [5], the velocity spectra provide a good comparison of the long-period responses. The long-period spectral velocities at the various sites increase with increasing depth to bedrock, with the weakest long-period response occurring at the INS rock site and the strongest longperiod response at GMT, where there is about $300 \mathrm{~m}$ depth to the bedrock. The INS site, as discussed earlier, produces a velocity response spectrum which is peaked at short periods and is almost flat at long periods. The PEL spectrum shows only moderate amplification (by less than a factor of 2) of the rock motion at periods greater than about $1 \mathrm{~s}$. The spectral peak around $0.4 \mathrm{~s}$ corresponds to the site's fundamental period, but as indicated earlier its amplification in this earthquake and most others is stronger in the along-valley direction shown in the response histories (Fig. 4) than in the cross-valley direction shown here for the velocity response spectrum.

The velocity response spectrum from the long-period GMT site shows no significant difference from the INS rock spectrum up to about $0.4 \mathrm{~s}$ period, apart from some attenuation at very short periods, but gives the largest amplifications at longer periods despite the fact that the complete ground motion was not recorded at this site. The ELS site, which is located between the short-period PEL site and long-period GMT site, indicates a combined effect of short- and long-period responses, similar to what was observed in the time histories compared in the alongvalley direction. For the cross-valley components shown here, the ELS spectrum is stronger than the PEL spectrum around 0.4 $s$ period, but the PEL spectrum is stronger for its resonant along-valley motion.

The combination of response characteristics of the short-period PEL site and of the long-period GMT site at the ELS site located between them is shown clearly by the transfer functions of the N54E (along-valley) components of the Fourier spectra of acceleration with respect to the INS rock site motion (Fig. 6). A divider is drawn at $2.25 \mathrm{~Hz}(0.44 \mathrm{~s})$ to differentiate the site characteristics. The low-frequency filter cutoff initiated at 0.6 $\mathrm{Hz}$ and thus the transfer functions of frequencies below $0.6 \mathrm{~Hz}$ should be ignored. 

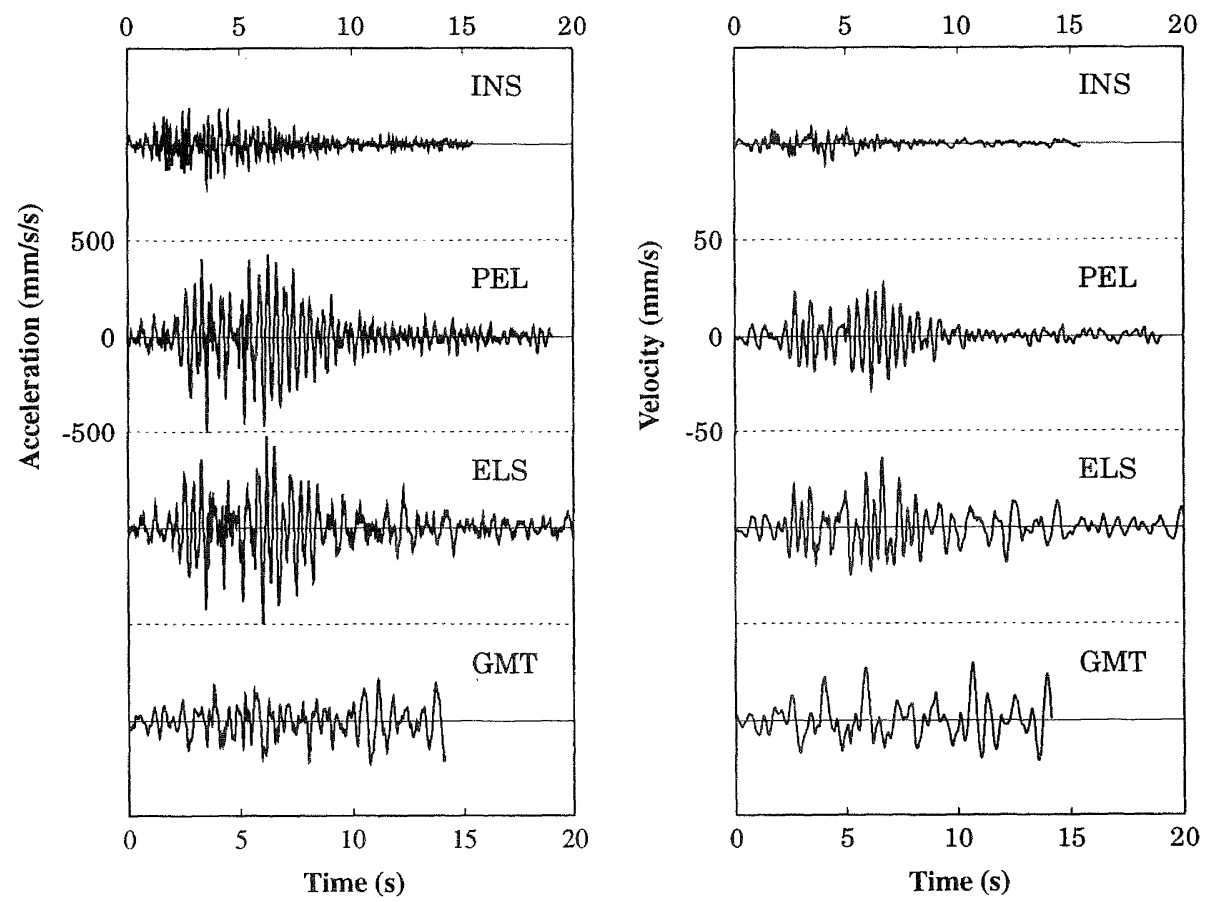

Fig. 4 Comparison of $20 \mathrm{~s}$ segments of acceleration and velocity histories in the along-valley direction in the 1973 central North Island earthquake for four sites located across the lower part of the Hutt Valley on different depths of sediment. See Fig. 1 for site locations, and Table 2 for description of geological conditions at each site.

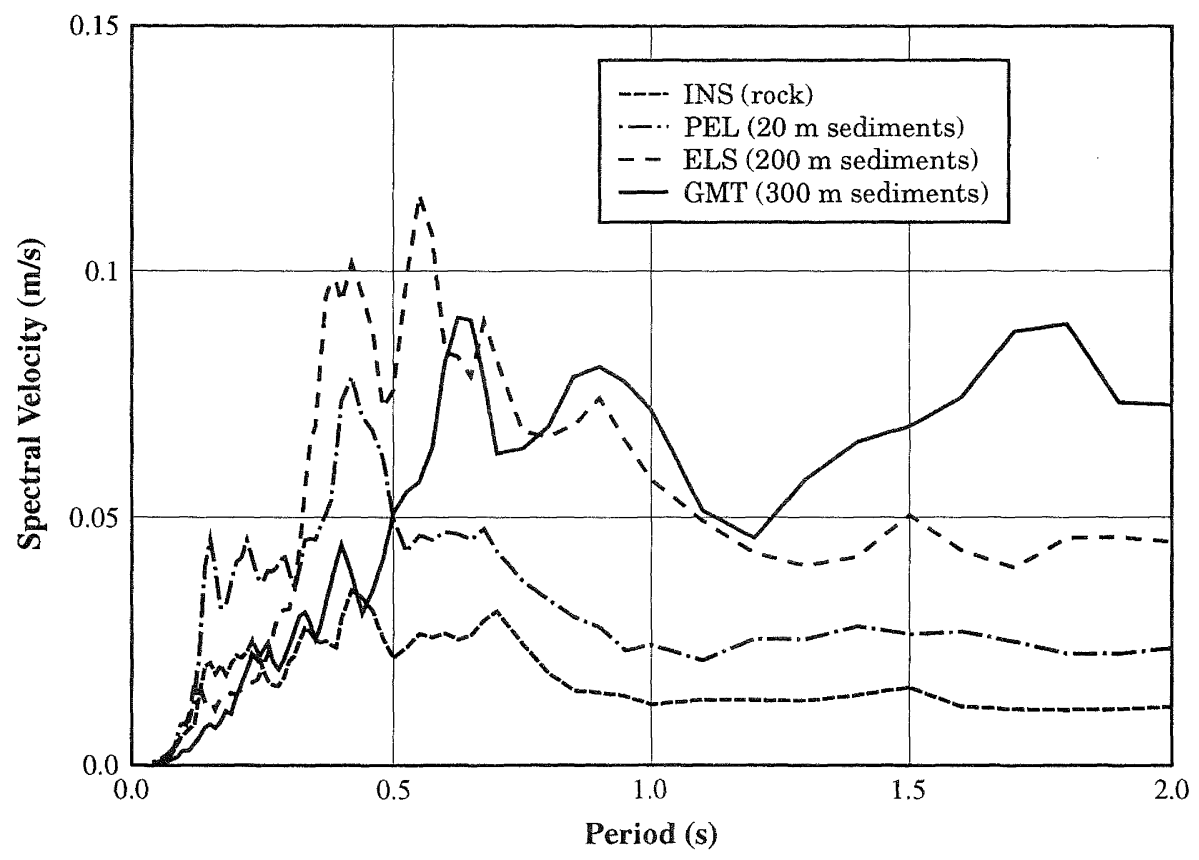

Fig. 5 The $5 \%$ damped velocity response spectra in the cross-valley direction in the 1973 earthquake for the four sites located across the lower part of the Hutt Valley. Note the increase in strength of long-period motion with depth of sediment. 


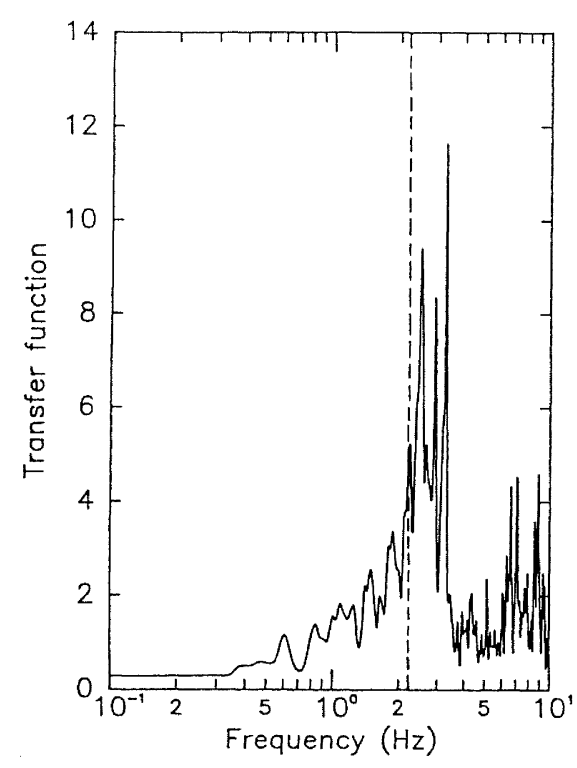

(a) PEL (20 m deep sediments)

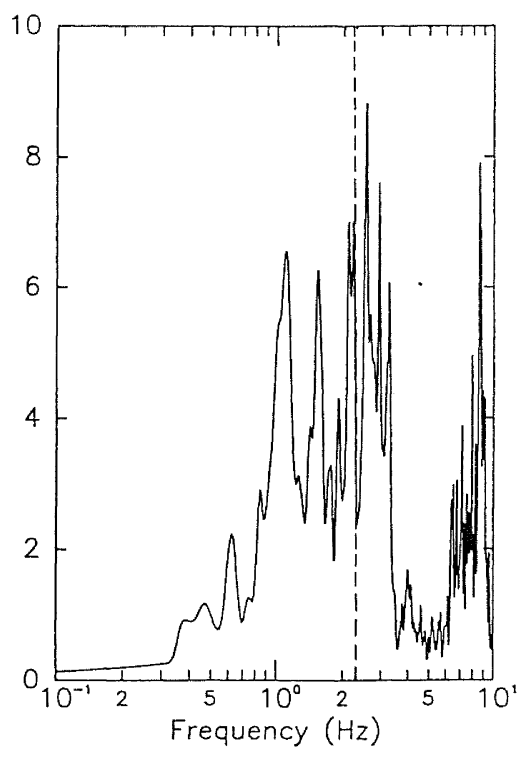

(b) ELS (200 m deep sediments)

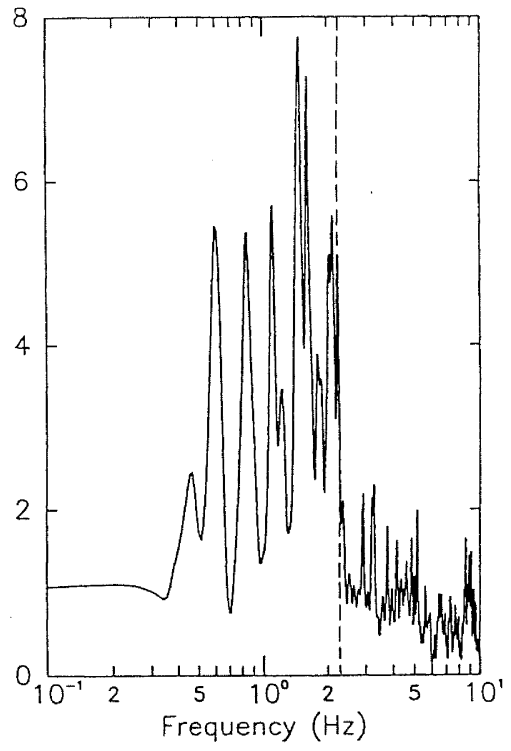

(c) GMT (300 m deep sediments)

Fig. 6 Systematic variations across the lower valley of the Fourier spectral ratios (transfer functions) with respect to INS for the N54E (along-valley) components of the deep distant $\mathrm{M}_{\mathrm{L}} 7.0$ earthquake of 1973. The amplification is largest for frequencies greater than $2.25 \mathrm{~Hz}$ at the shallow PEL site and for frequencies less than $2.25 \mathrm{~Hz}$ at the deep GMT site, while the intermediate ELS site combines the PEL and GMT response characteristics. Note variation in scales of vertical axes.

The PEL site, the accelerograph site with the smallest depth of sediment of those outside Zone 1 , which is located adjacent to the edge of the valley, produced strong amplification in a narrow frequency band starting from $2.25 \mathrm{~Hz}$. The deepest sediment site, GMT, with $300 \mathrm{~m}$ to bedrock, showed no marked amplifications at frequencies greater than $2.25 \mathrm{~Hz}$, but significantly amplified the motion below $2.25 \mathrm{~Hz}$. The ELS site, located between PEL and GMT on $200 \mathrm{~m}$ of sediments, gave amplifications both above and below $2.25 \mathrm{~Hz}$. Further, the deepest site produced two prominent peaks at frequencies less than $1 \mathrm{~Hz}$ which were much less obvious at ELS. This systematic variation in ground amplifications suggests that the total thickness of sediment at each site plays a major role in determining the local dynamic characteristics. A similar study carried out for central Wellington city failed to produce such conclusive evidence [8].

The lowest frequency of the peaks exceeding an amplification of 5 at GMT was $0.6 \mathrm{~Hz}$, which is the lowest valid frequency in the transfer functions because it corresponds to the lowfrequency cutoff initiation frequency for the reference INS site. However, the strengths of the records allowed the low-frequency cutoff initiation frequencies for the Fourier spectra of these 1973 records to be reduced to $0.5 \mathrm{~Hz}$ for PEL and ELS, and to 0.4 $\mathrm{Hz}$ for GMT. The transfer function peak at $0.6 \mathrm{~Hz}$ corresponded to prominent Fourier spectra peaks for both orthogonal components at GMT, and small amplitude peaks at this frequency were also detectable at PEL and more clearly at ELS.
Given the $300 \mathrm{~m}$ depth of sediments at GMT, the onedimensional shear-beam theory requires an average shear-wave velocity of $720 \mathrm{~m} / \mathrm{s}$ for a fundamental-mode frequency of 0.6 $\mathrm{Hz}$, which is a plausible although somewhat high velocity for the types of sediments underlying this site. This frequency thus appears to be a candidate for the fundamental-mode frequency of the valley as a whole. However, there is a possibility that the fundamental-mode frequency of the Hutt Valley may be even lower than $0.6 \mathrm{~Hz}$, with indications of peaks at frequencies of $0.5 \mathrm{~Hz}$ or less in some records.

Comparisons of the peak ground accelerations (PGAs) recorded at the sites and their velocity response spectra (Fig. 5) emphasize that the PGAs are often not a good representation of the local site effects. PGA values are influenced by the highfrequency motion and often PGAs have smaller values at longperiod sites such as deep alluvial and soft sites, which may attenuate the high-frequency content, than at sites which produce strong short-period peaks. Although PGAs are often considered to represent the strength of the shaking by structural designers, the spectral ratios, which provide the relative strength of the ground motion at various periods, should be given consideration when assessing local site effects. In this particular example, the motions at the rock INS site and at the long-period GMT site attain almost the same PGA values. Nevertheless, the velocity spectra indicate that the maximum energy, which is proportional to the square of the spectral velocity, imparted in this earthquake to a long-period $(1.0 \mathrm{~s}-2.0 \mathrm{~s})$ structure located near the GMT site would have been approximately 12 to 64 times that imparted to it if the structure was located on rock at INS. 
A second set of records demonstrating the different character of the various strong-motion sites in the Hutt Valley was produced by the Cape Palliser earthquake of 4 October 1990. Although only of magnitude $M_{L} 4.9$, this event centred $70 \mathrm{~km}$ from the Hutt Valley, contained a significant portion of its energy at longer periods. Plots of the ground velocities calculated from the recorded accelerations and of the 5\% damped acceleration response spectra for the N36W components are shown in Figs. $7 \mathrm{a}$ and $7 \mathrm{~b}$. The peak value of the velocity at the shallow PEL alluvial site was amplified by a factor of 2.3 with respect to the INS rock site, about $400 \mathrm{~m}$ away. The PEL site has been identified as a site with directional short-period resonance $[5,7,12]$, exhibiting strongly amplified peaks in a narrow frequency band repeatedly in different earthquakes. The resonant direction for PEL is along the valley, but even the cross-valley component in this earthquake was dominated by motion at about $0.4 \mathrm{~s}$ period corresponding to the site period. The maximum ground velocity at the deep sediment NZGS site was 4.5 times stronger than at INS, and its velocity record showed a predominant period corresponding to the acceleration response spectrum peak at $1.2 \mathrm{~s}$ period. The NZGS spectrum also has a prominent short-period peak, at a shorter period than the strongest peak at PEL. A similar short-period peak has occurred in several records from NZGS, but is not apparent in GMT records. It could possibly be induced by near-surface $(<10 \mathrm{~m})$ soft deposits of low seismic velocity as described by Perrin [6].

\section{SITE CHARACTERISTICS}

We have now demonstrated that marked site response effects exist in earthquake motions recorded in the Hutt Valley. In the following sections, we will examine in detail the response characteristics at various sites.

\section{Rock Sites}

In the events considered, the HAY and NAE rock sites produced a total of only three records which were large enough to be digitized. The 1968 Palliser Bay and the deep 1973 events each produced a record at HAY while the 1977 Cook Strait event gave a record at NAE. The record from the 1968 event has not been analyzed and the records from the 1973 and 1977 are discussed in this section. The two horizontal components of the 5 percent damped acceleration response spectra for HAY and NAE are compared against the corresponding INS spectra in Fig. 8.

The spectra for the HAY and NAE rock sites show characteristics similar to those of INS, having dominant shortperiod peaks and relatively low amplitude long-period response. However, the ground motions are significantly amplified in the short-period range at HAY with respect to INS, with the ratios of the HAY to INS 5\% damped response spectrum accelerations reaching a factor of 3.2 at $0.085 \mathrm{~s}$ and 3.0 at $0.17 \mathrm{~s}$ in the N54E and N36W directions respectively. These short-period amplifications may be a topographical effect or may be associated with the well-compacted cohesive fill of up to $4 \mathrm{~m}$ depth present at the site [6], or a combined effect of both.

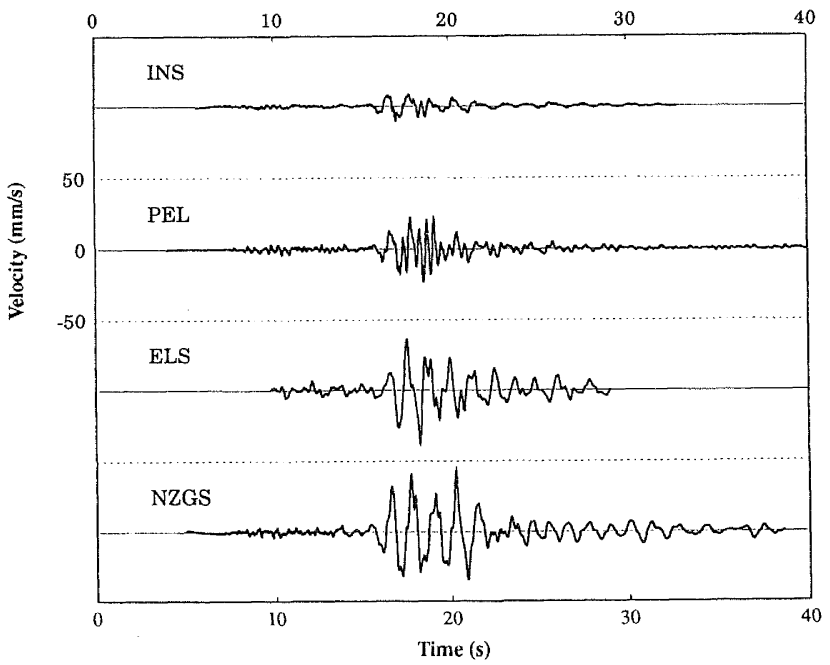

a. Velocity histories

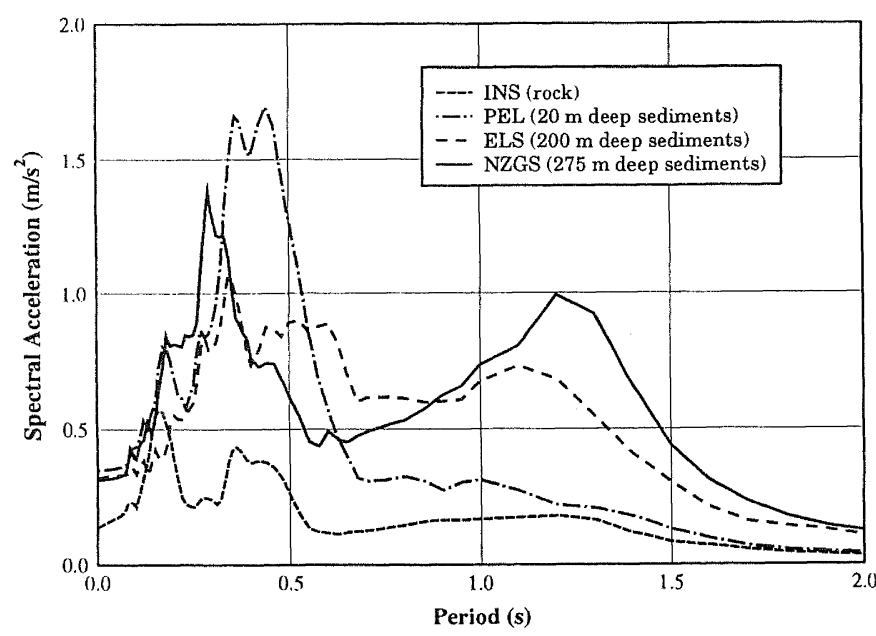

b. $5 \%$ damped acceleration response spectra

Fig. 7 Comparison of the cross-valley components in Cape Palliser Event 1. Note the increase in amplitude and predominant period as the depth of sediment increases from INS to NZGS. 


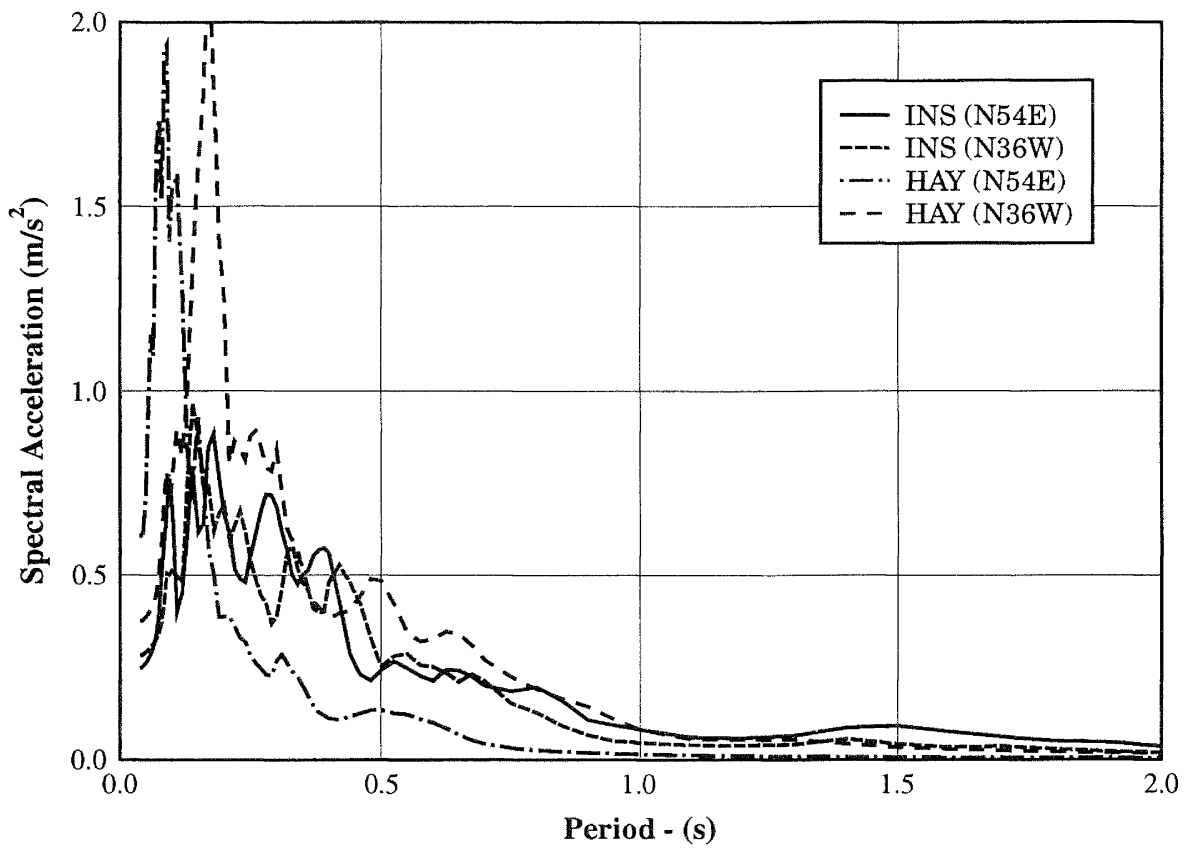

a. 1973 earthquake, HAY and INS

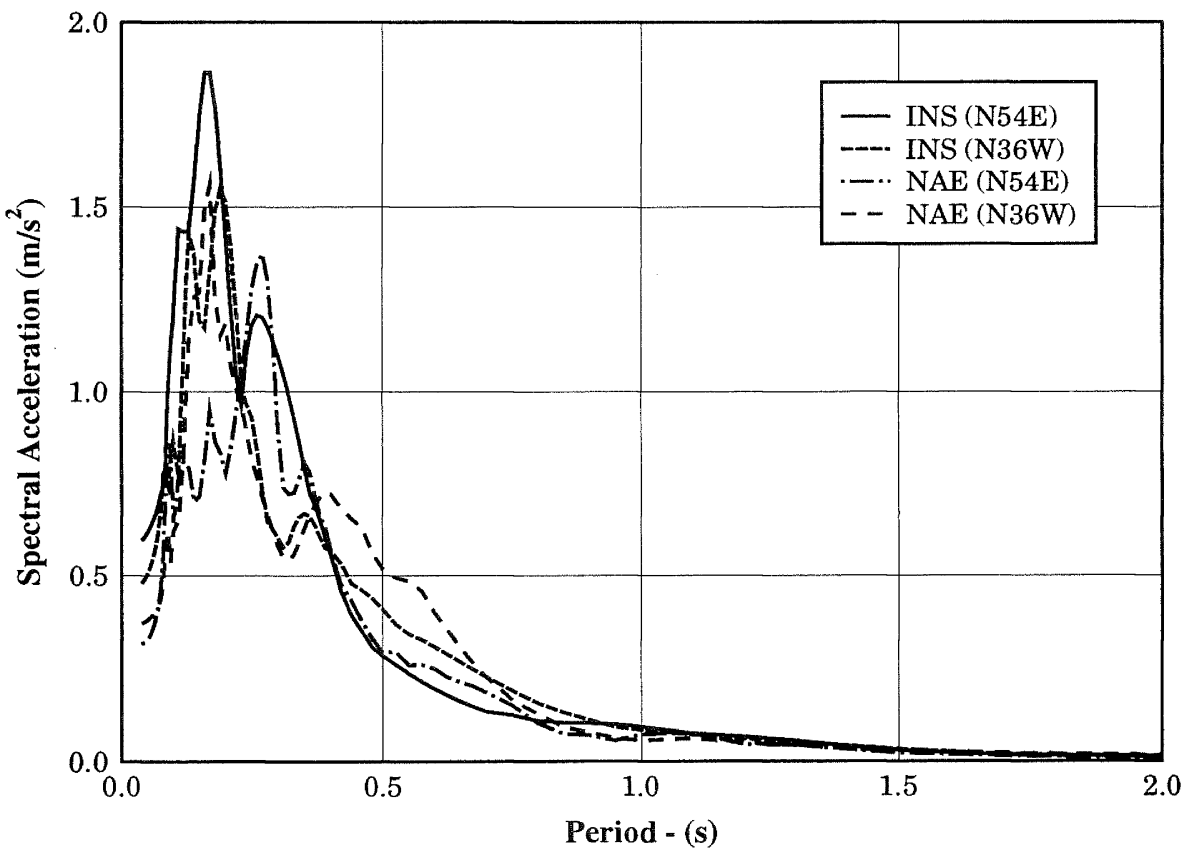

b. 1977 earthquake, NAE and INS

Fig. 8 The 5\% damped acceleration response spectra of the rock sites. Note the dominance of short periods. 
The NAE site generally produces a good match against the INS spectra, in particular for the N36W component (Fig. 8b). The short-period $(<0.23 \mathrm{~s})$ de-amplification seen in the N54E component is not unexpected as the accelerograph is located on the basement of an underground reservoir, which may filter out short-period motions.

In general, the ground motions at rock sites are characterised by short-period peaks with maximum acceleration response spectrum peaks appearing between 0.1 to $0.25 \mathrm{~s}$. Short-period amplifications of up to 3 with respect to INS such as calculated for HAY may be expected in Zone 1 of the ground shaking microzonation because: (a) there are small remnants of old weathered terraces present at various locations in this zone [14], and (b) the steep slopes in Zone 1, particularly along the Wellington fault, may exhibit topographical effects. This spectral amplification factor of up to 3 within Zone 1 is in line with the microearthquake observations [13]. The amplitudes of the longer-period motions are relatively small for these events at these rock sites. Larger, shallow, distant earthquakes are likely to produce relatively larger amplitude longer-period motion at Zone 1 sites than that demonstrated by the records from the 1973 and 1977 events.

\section{Soil Sites}

This section summarises the response characteristics of the soil sites PEL, ELS, GMT and NZGS. Detailed transfer function analyses were performed for the PEL, ELS, GMT and NZGS accelerograms from the 1973, 1977 and February 1990 earthquakes in our WRC study [7]. The mean amplifications of the acceleration response spectra were also calculated for PEL with respect to INS from ten events recorded at both sites $[5,7]$.

The three soil sites located across the lower part of the valley (PEL, ELS and GMT) have systematic variations in their site responses, as shown earlier in the transfer function plot of their along-valley responses in the 1973 earthquake (Fig. 6).

The PEL site situated adjacent to the edge of the valley on 20 $\mathrm{m}$ of sediment strongly amplifies the INS rock motion at short periods, particularly in the N54E direction, as shown repeatedly in many earthquakes. The 5\% damped acceleration response spectrum ratios between PEL and INS were calculated for ten earthquakes. The average spectral ratio for the ten earthquakes had a well-defined peak of 4.1 at $0.35 \mathrm{~s}$ for the along-valley N54E component, while the N36W component had a less welldefined peak reaching maximum of 3.3 at the same period. The mean log ratio at zero period over the 20 components gave a factor of 2.2 between the horizontal peak ground accelerations of PEL and INS. The mean log spectral ratios dropped smoothly in the period band of $0.5 \mathrm{~s}$ to $1.0 \mathrm{~s}$, to a nearly constant factor of about 2 for periods in excess of $1.0 \mathrm{~s}$. Individual records gave maximum 5\% damped acceleration response spectrum amplifications in the period band of $0.25 \mathrm{~s}$ to $0.5 \mathrm{~s}$ reaching values of 6 for the 1973 and 1977 earthquakes and 10 for the February 1990 Weber earthquake.

The records showed that a broad-band amplification may be expected in both directions at ELS which comprises $200 \mathrm{~m}$ of sediments. For short periods (less than about $0.5 \mathrm{~s}$ ), the site produced comparable amplifications to that obtained for PEL, while it showed stronger amplification than PEL at longer periods. A strong response spectrum amplification peak for this site may be expected at around $1.0 \mathrm{~s}$ as well as at short periods. The spectral ratio calculations for the 1973 and 1977 events showed amplifications with respect to the INS motion of up to
6.6 in the short-period band and of up to 7.2 for longer periods around $1.0 \mathrm{~s}$. The long-period peak was not significant in the spectra for the 1977 event which had little long-period energy present in the rock spectra.

The GMT site, on $300 \mathrm{~m}$ of sediments, consistently produced broad-band amplifications, with a prominent peak around $1.0 \mathrm{~s}$ which had the strongest amplification in the 1973 and 1977 events. Maximum 5\% damped acceleration response spectrum ratios of 10 at $0.95 \mathrm{~s}$ period for the $\mathrm{N} 36 \mathrm{~W}$ component in the 1973 earthquake and 7.5 at $0.85 \mathrm{~s}$ period for the N54E component in the 1977 earthquake were obtained. A strong amplification peak may also occur in the period range of 1.5-2.0 $s$ at GMT, as indicated previously in the discussion of the velocity response spectra (Fig. 5) and Fourier spectral ratios (Fig. 6). The records from both 1973 and 1977 earthquakes showed de-amplification of the rock motion at short periods less than about $0.25 \mathrm{~s}$. A similar result was obtained at a nearby site in the microearthquake study [13].

The site in the central Hutt area, NZGS, which is underlain by $275 \mathrm{~m}$ of sediments, showed broad-band amplifications. Acceleration response spectrum amplification peaks exceeding 10 at around $1.3 \mathrm{~s}$ period in the N54E component and at around $1.5 \mathrm{~s}$ in the N36W component were dominant in the February 1990 Weber earthquake. Peaks at similar periods with amplifications of about 5 were obtained in the two Cape Palliser earthquakes of October 1990. Unlike at the GMT site, no significant deamplifications of the rock motions were observed in the short-period band at NZGS, with strong short-period peaks sometimes present.

Some of these points are illustrated by the ratio with respect to the INS rock site of the 5\% damped acceleration response spectra shown in Fig. 9 for the 1973 central North Island earthquake. PEL has its strongest amplification at short period, particularly in the N54E direction. ELS has similar response to PEL at short period, but also has significant amplification at periods around $0.85 \mathrm{~s}$ to $1.0 \mathrm{~s}$. GMT attenuates the rock motion at very short period but shows strong amplifications at long periods, in excess of $0.5 \mathrm{~s}$

\section{RECENT EARTHQUAKES}

Since completion of the WRC study in May 1991, there have been three distant deep events with magnitudes exceeding 6 , which triggered a number of strong-motion accelerographs in the Hutt Valley (Tables $1 \& 3$ ). It is of interest to compare the site characteristics shown in these earthquakes with those determined in the WRC study and to examine the response nature of our new sites, NAES, WAI and CFT. In particular, the CFT site which is on reclamation land in the south-east corner of the Hutt Valley has been placed in the same microzone as the nearby ELS site, and the new records offer the possibility of evaluating this zonation.

\section{July 1991 Event under Taupo}

The first of these events was centred $71 \mathrm{~km}$ deep in the Taupo region at an epicentral distance of about $230 \mathrm{~km}$ from the Hutt Valley. The ground shaking was not strong enough to trigger the digital accelerograph at the reference INS site, but records were obtained from PEL, NZGS, NAES and WAI, with peak ground accelerations ranging from $0.0027 \mathrm{~g}$ at PEL to $0.0082 \mathrm{~g}$ at NAES (Table 3). The strength of the signal at PEL was very small and severe filtering was required for processing. Hence, the record could not be used for comparison over a useful frequency range. 


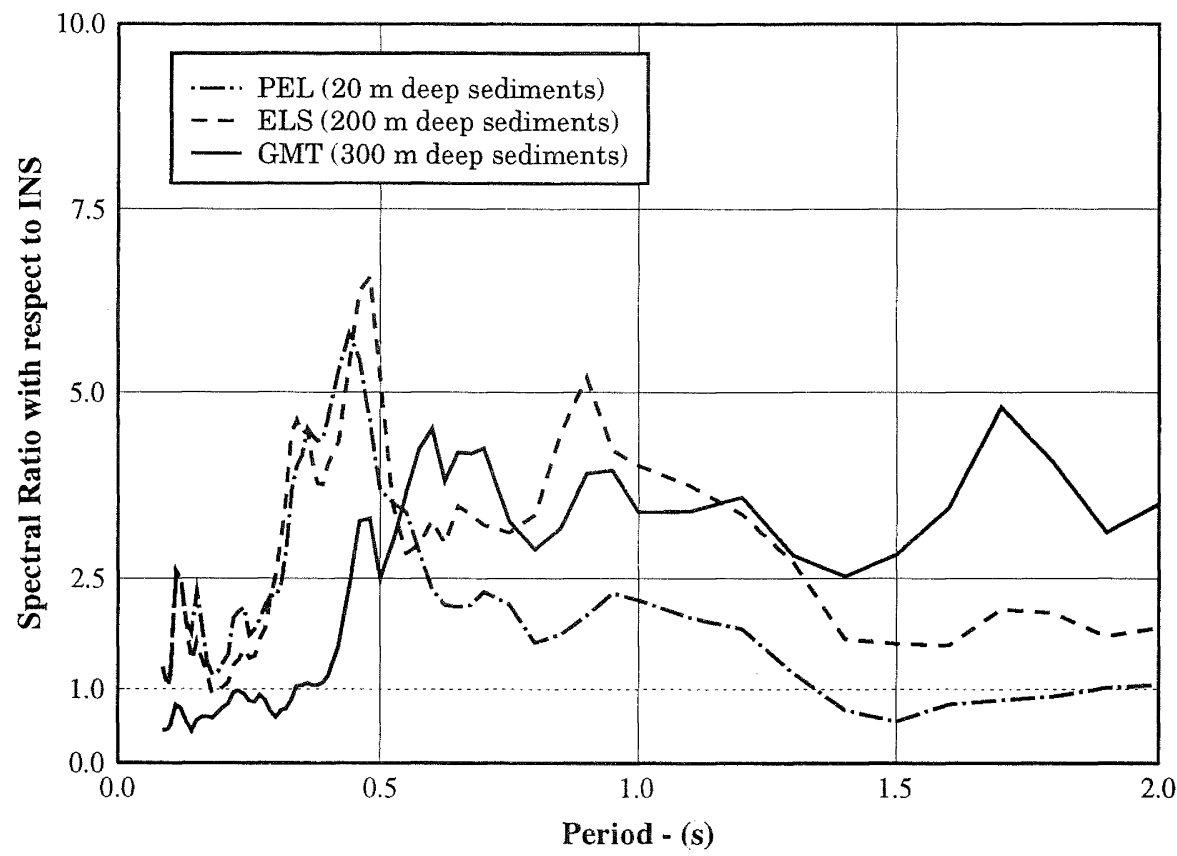

$a_{n} \quad$ Along-valley direction

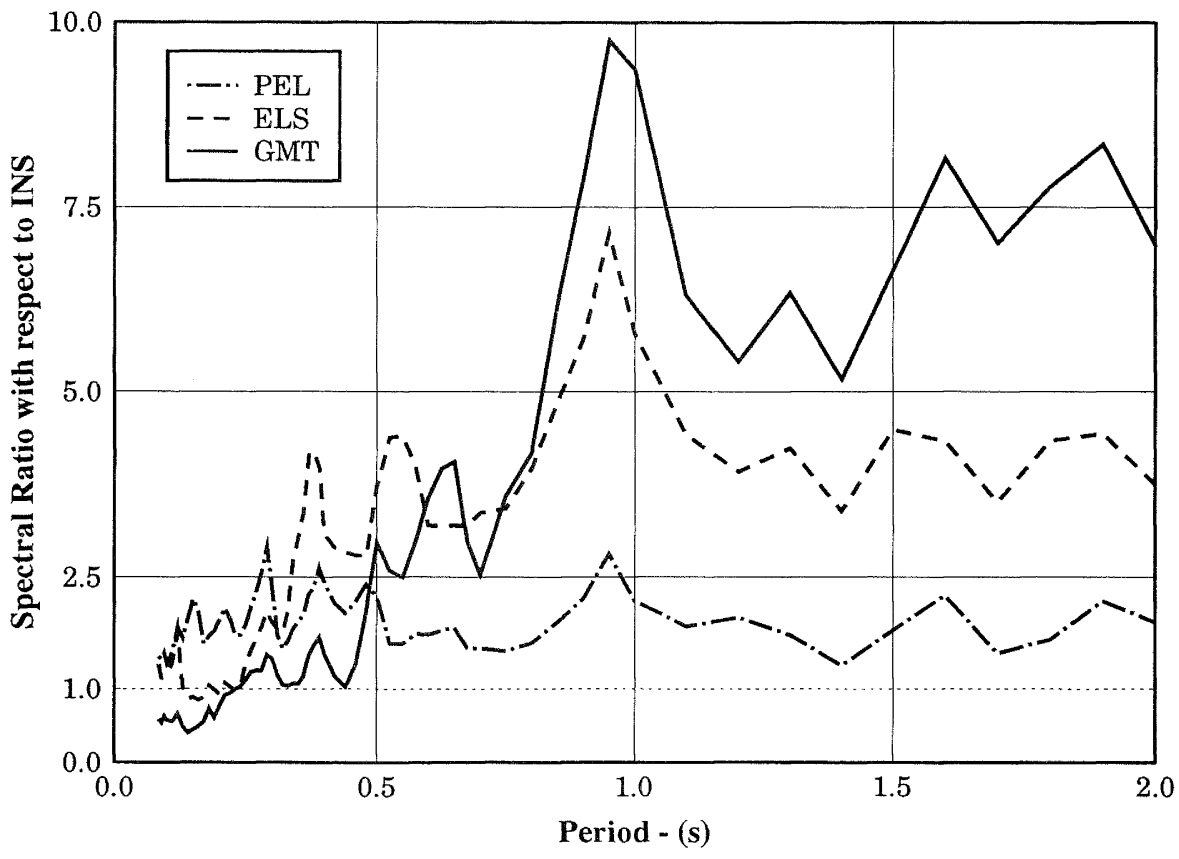

b. Cross-valley direction

Fig. 9 The 5\% damped acceleration response spectrum ratios of the three soil sites with respect to the reference site in the 1973 earthquake. Note the dependence of the long-period amplification on the depth of sediment. 
The 5\% damped acceleration response spectra in the two orthogonal directions are shown in Fig. 10 for NZGS, NAES and WAI.

The NZGS spectra are typical of those obtained previously from this site (eg: Fig. 7b) with peaks appearing in the short-period range $(\sim 0.35 \mathrm{~s})$ and at longer period $(\sim 1.4 \mathrm{~s})$. The trigger level at NZGS was set to a larger value than that at NAES and WAI because of the high noise level present at NZGS. This may be partly responsible for the shorter record duration of $18 \mathrm{~s}$ at NZGS compared to the duration of $40 \mathrm{~s}$ at NAES and WAI. This may have slightly weakened the calculated long-period spectral accelerations at NZGS.

The spectra for both horizontal components of the motion at the NAES site were dominated by peaks at medium to long-period, but also contained a short-period peak. The along-valley component had prominent peaks at $0.22,0.46 .0 .75,0.85$ and $1.1 \mathrm{~s}$, whereas the cross-valley component showed peaks at $0.22,0.50,0.67$ and $0.85 \mathrm{~s}$. The $0.85 \mathrm{~s}$ peak of the along-valley component was the strongest in the acceleration spectra (Fig. 10). The long-period nature of the response was more obvious in the velocity spectra, which were dominated by smooth peaks in the period range of $0.75 \mathrm{~s}$ to $1.1 \mathrm{~s}$. This long-period dominance is consistent with Taber \& Smith's microearthquake results, for which the smoothed mean Fourier spectral ratio with respect to INS had its strongest peak at around $1 \mathrm{~Hz}$, with an amplification of 14.5. The spectra of both components in the Taupo earthquake also show a prominent short-period peak around $0.22 \mathrm{~s}$. This peak, corresponding to a frequency of 4.5 $\mathrm{Hz}$, is present but much less prominent in Taber \& Smith's microearthquake results.

The WAI site, corresponding to the microearthquake survey site L17 [13], had the strongest peaks of its acceleration response spectra in this event at longer periods than those of NAES. The period of the strongest peak at $1.2 \mathrm{~s}$ corresponds well with the value of $1.1 \mathrm{~s}(0.92 \mathrm{~Hz})$ at the peak of the mean Fourier spectral ratio from the microearthquake results. A prominent short-period peak at $0.29 \mathrm{~s}(3.5 \mathrm{~Hz})$ in Taber \& Smith's results is not apparent in the response spectra from this event.

In these comparisons with the microearthquake results, it should be borne in mind that spectra from single events are being compared with spectra averaged over several events in the microearthquake study.

The long-period nature of the Taupo earthquake provided excitation which demonstrates clearly the response characteristics of the NAES and WAI sites. Both show much stronger response than the NZGS site in the $0.4 \mathrm{~s}$ to $1.25 \mathrm{~s}$ period band, although the much deeper deposits at NZGS show stronger response at longer periods.

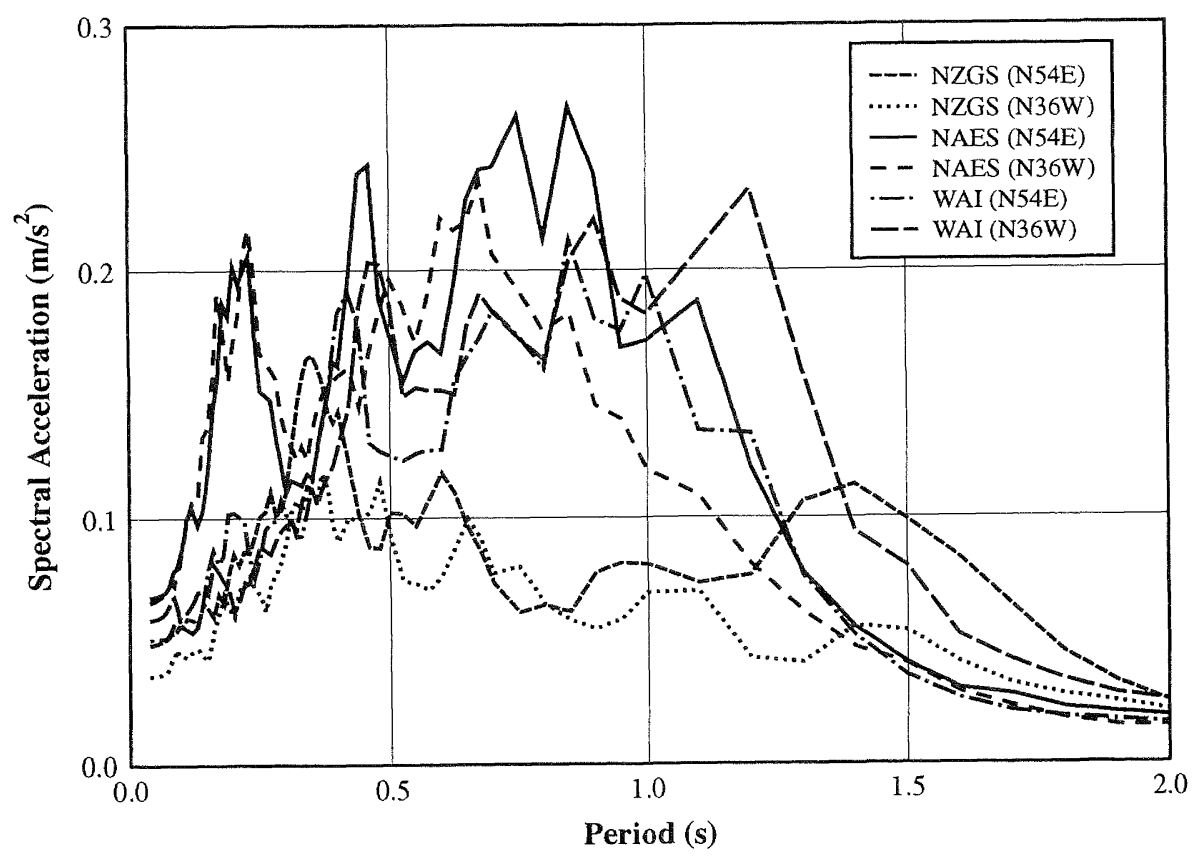

Fig. 10 Comparison of the $5 \%$ damped acceleration response spectra of three sites in Zone 5 in the 1991 event under Taupo. Note the strength of the spectra at the newly instrumented NAES and WAI sites in the $0.5 \mathrm{~s}$ to $1.2 \mathrm{~s}$ period band compared to the deeper alluvial NZGS site, which shows stronger spectral accelerations at longer periods. 
September 1991 Event Offshore from Bulls

The second recent earthquake was of $M_{L} 6.3$ centred $87 \mathrm{~km}$ deep offshore from Bulls at an epicentral distance of about 110 $\mathrm{km}$ from the Hutt Valley. The ground motions in the Hutt Valley from this earthquake were generally dominated by strong high-frequency components, despite its moderate magnitude and large distance from the valley. The CFT and NZGS recorders triggered on the $\mathrm{S}$-wave and the others on the $\mathrm{P}$-wave. The strong portion of the $S$-wave was recorded at all sites, with the peak ground accelerations of the $\mathrm{N} 36 \mathrm{~W}$ component ranging from $0.015 \mathrm{~g}$ at INS to $0.055 \mathrm{~g}$ at NAES.

The long-period character of many of these sites is not apparent from the acceleration response spectra, shown for the crossvalley components in Fig. 11a, but is much more obvious in the response spectrum ratios of Fig. 11b. The spectral ratios for NAES, WAI, CFT and NZGS are all dominated by peaks in the long-period range (greater than $1 \mathrm{~s}$ ), with the maximum amplifications exceeding 5 for all these sites, reaching close to 10 for WAI and exceeding 10 for NAES. Note that these amplification peaks appear genuine, as there is no obvious dip in the reference INS rock spectrum in the period range of 1.2$1.3 \mathrm{~s}$ associated with these peaks, and the PEL amplification is nearly constant across the period band containing the peaks at the other sites. Only PEL shows its strongest amplification peak at a period less than $0.5 \mathrm{~s}$, with a maximum amplification of 5.5 at $0.42 \mathrm{~s}$. NAES, WAI and CFT also have short-period (less than $0.5 \mathrm{~s}$ ) amplification peaks exceeding 5, as well as their dominant long-period peaks.

This was the first record with PGA exceeding $0.2 \% \mathrm{~g}$ obtained at CFT, which is located in Zone 3-4 along with ELS. The similarities shown by the two sites are encouraging in that the spectra calculated for CFT show narrow-banded short-period peaks and a broad long-period band amplification, like previous records from ELS. Unlike ELS records, a trough in a band at short period $(0.25 \mathrm{~s}-0.35 \mathrm{~s})$ is seen in the spectral ratio plot, although there are strong peaks present in the INS spectra in that period band. A dip in the mean spectral ratio is seen for site L15 of Taber \& Smith [13], located close to CFT, in the same period band.

\section{May 1992 Event near Blenheim}

The third recent event had a magnitude of $M_{L} 6.2$, and was centred about $30 \mathrm{~km}$ south-west of Blenheim. The focal depth of this earthquake was $90 \mathrm{~km}$ and the preliminary source location gave an epicentral distance of about $110 \mathrm{~km}$ from the Hutt Valley. The peak ground accelerations in this event were generally somewhat less in the study area than in the Bulls earthquake, but it gave the largest number of records obtained in the Hutt Valley in a single event. All the digital accelerographs and a few MO instruments recorded the ground motions at various locations in the Hutt Valley.

Fourier spectra calculated for the reference INS site indicated that the bedrock motion was dominated by components in the range $2.0 \mathrm{~Hz}$ to $4.5 \mathrm{~Hz}$, but there was significant energy to frequencies as low as $0.5 \mathrm{~Hz}$. Although the acceleration response spectra for all sites had their strongest peaks at periods less than $0.5 \mathrm{~s}$, some of the Fourier spectra showed prominent peaks at frequencies less than $1 \mathrm{~Hz}$ (eg: CFT $0.84 \mathrm{~Hz}$ in both components; NAES $0.8-1.0 \mathrm{~Hz}$ in the N54E component; ELS $0.6-1.0 \mathrm{~Hz}$ in the N36W component; WAI $0.8-0.85 \mathrm{~Hz}$ in both components). Only at WAI were low-frequency peaks prominent in the acceleration response spectra. However, as for the Bulls earthquake, the amplifications are apparent in the acceleration response spectrum ratios (Fig. 12).

The WAI site had its characteristic peak at $1.2 \mathrm{~s}$ period, with amplification exceeding 30 in both components (note that the spectral ratios of WAI shown in Fig. 12 have been multiplied by a factor of 0.5 ). This $1.2 \mathrm{~s}$ period, which is in good agreement with a possible resonant period of $1.1 \mathrm{~s}(0.9 \mathrm{~Hz})$ predicted for this site by Stephenson \& Barker [10], gave the maximum spectral ratio in the Bulls earthquake (Fig. 11b), but the amplifications are 2-3 times greater in the Blenheim event. Although the spectral ratio peaks correspond to the period which dominated the response at WAI, it is possible that the reference motion used to calculate the spectral ratio does not truly represent the input motion, leading to the very large values of the amplifications. This point requires further investigation.

NAES showed its greatest amplification of $10-12$ between 0.95 $s$ and $1.2 \mathrm{~s}$, similar values as in the Bulls event. The strongest amplifications at NZGS were less than 5, slightly less than typical maximum amplifications in earlier earthquakes, but as previously showed broad-band amplification for periods up to $1.5 \mathrm{~s}$. PEL as usual had its strongest amplification at a short period, with the maximum value of 5.7 at $0.23 \mathrm{~s}$ in the N54E component, with secondary peaks around $0.4 \mathrm{~s}$ and 0.6 to 0.65 s. Its amplification at long period in this earthquake is typical of the PEL site, where there is on average an amplification of 2 for periods exceeding $1.0 \mathrm{~s}$.

CFT showed maximum amplifications of around 10 in both components, with the strongest peaks at periods exceeding 1.0 $\mathrm{s}$, as in the Bulls earthquake. The short-period band $(0.25 \mathrm{~s}-$ $0.35 \mathrm{~s}$ ) trough as seen in the Bulls event is also apparent in the two components. For the first time, a direct comparison with the response at the nearby ELS site is possible, with the CFT amplifications generally somewhat stronger, and considerably stronger for periods in excess of $1.0 \mathrm{~s}$.

In this particular earthquake, both CFT and ELS located in Zone 3-4 had stronger amplifications than NZGS in Zone 5. The dominant response spectrum ratio peak seen at a period around $1.8 \mathrm{~s}$ in the cross-valley direction has not previously been observed at ELS. NZGS was placed in Zone 5 principally because of the presence of long-period peaks $(\sim 1.3 \mathrm{~s}$ and $\sim 1.5$ s) in some strong-motion accelerograph records, indicating the possibility of strong long-period amplifications in larger magnitude events, rather than because of the amplifications shown in the microearthquake survey. Further comparison between these sites is required to ensure the appropriateness of the location of the boundary between Zone 3-4 and Zone 5 in the lower part of the valley.

\section{DISCUSSION AND CONCLUSIONS}

The analysis of strong-motion earthquake records obtained from the Hutt Valley sites has been presented to demonstrate and quantify microzone effects related to geological site conditions. The accelerograms used in this study are all from weak to moderate ground shaking which produced peak horizontal accelerations of up to about $10 \% \mathrm{~g}$ in the Hutt Valley. Although the characteristics of the sites are often repetitive between events, there have been unusual characteristics in some records such as a strong peak appearing outside the usual dominant period band, noted only on occasion because of the aberrant nature of earthquakes. As an input to planning for the mitigation of seismic hazard in future earthquakes, it is appropriate that we identify and quantify general characteristics of the various sites. 


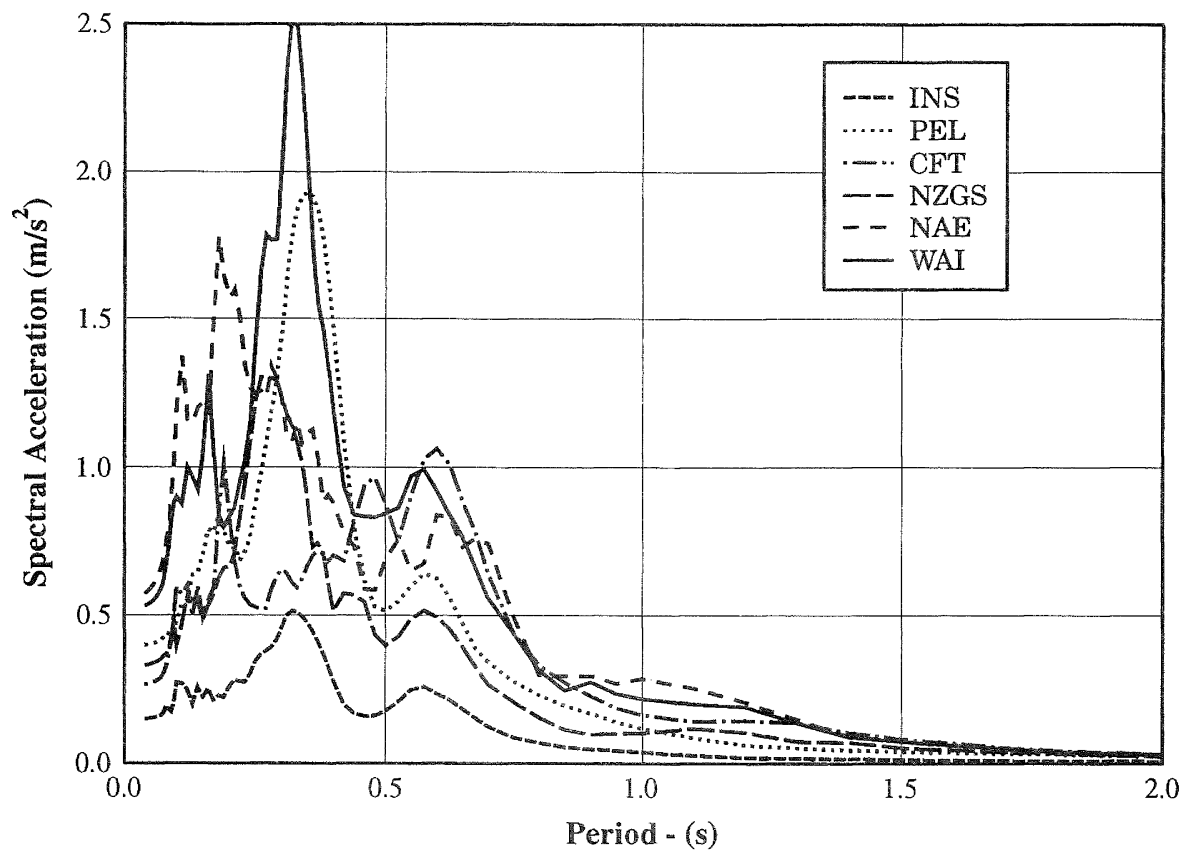

a. $5 \%$ damped acceleration response spectra

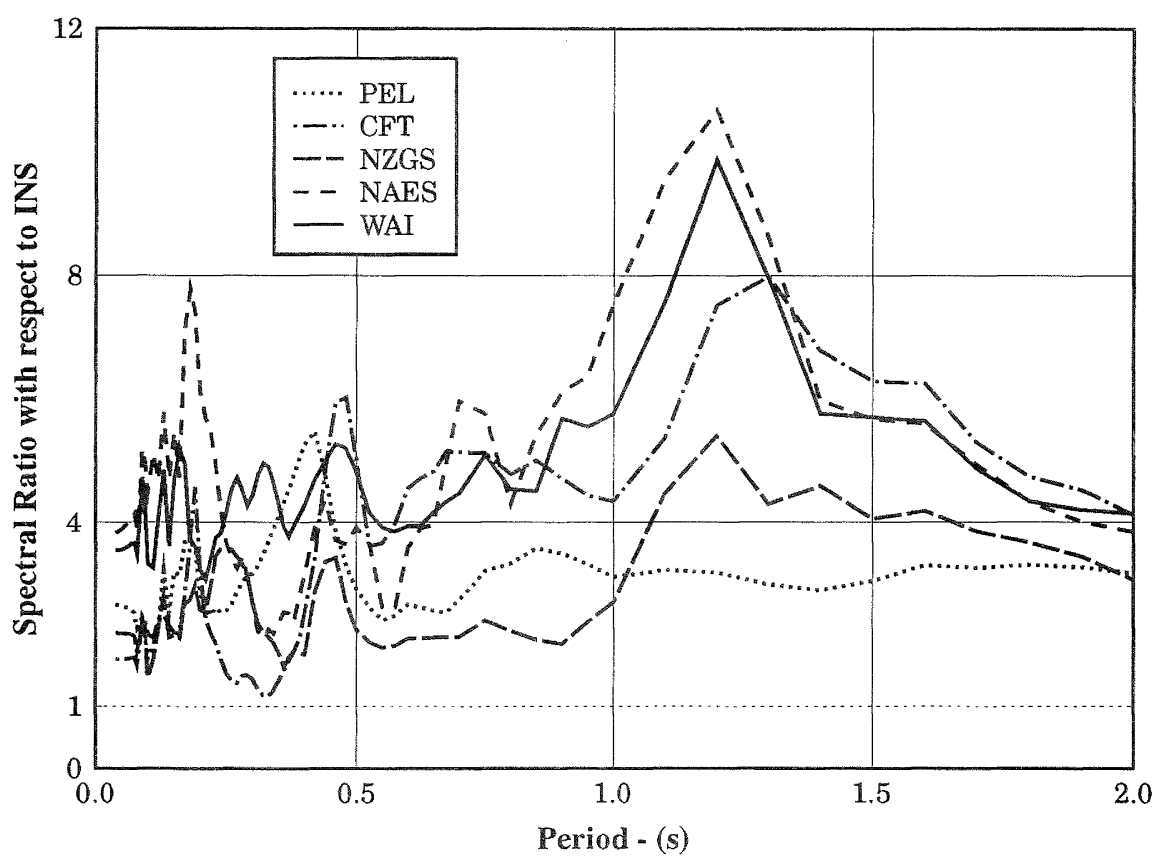

b. Ratios of $5 \%$ damped acceleration response spectra with respect to INS

Fig. 11 The cross-valley components in the 1991 event offshore from Bulls. Note the clearer presentation of the strong long-period amplification by the spectral ratio plots than by the response spectra. 


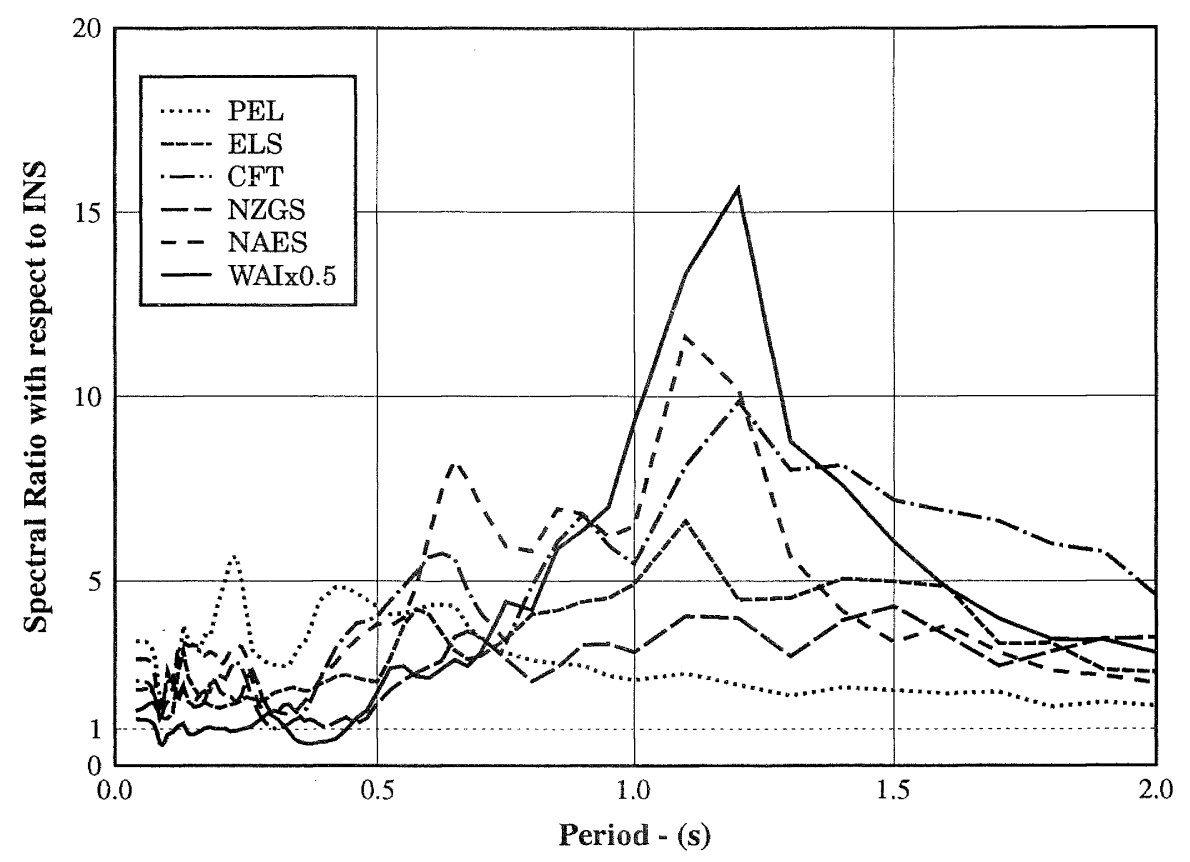

a. Along-valley direction

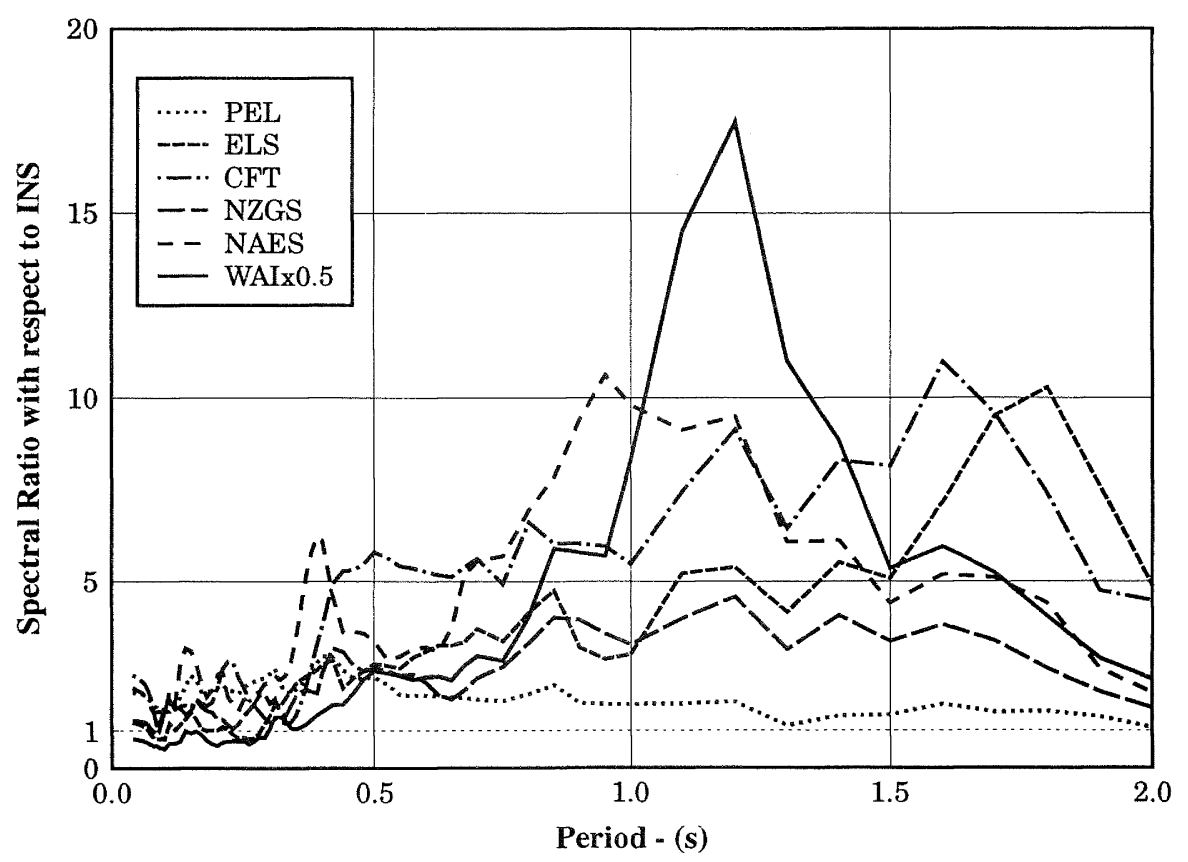

b، Cross-valley direction

Fig. 12 The 5\% damped acceleration response spectral ratios for the six soil sites with respect to the reference site in the 1992 event located near Blenheim. Note the very strong amplification at WAI at $1.2 \mathrm{~s}$, the same dominant period as in the Bulls event (Fig. 11b). The WAI spectral ratios have been divided by 2 for plotting, as indicated in the keys. 
The site characteristics are described in terms of their dominant period bands and associated amplifications, with sites categorised as short-period, long-period, a combination of shortand long-period, or resonant. The comparison of the results with those of a microearthquake study enable the individual site responses to be generalised for various microzones [14]. The conclusions drawn from our study are as follows:

1. Records from several different earthquakes showed that there are marked variations in the characteristics of ground motions at various sites in the Hutt Valley. The sites are closely spaced on the valley floor and on the rock along the edge of the valley, and range from bedrock to thick alluvium to soft sediment.

2. Response spectra from the three rock sites in the Hutt Valley showed that these sites respond dominantly in shortperiod bands, with the peak of the acceleration response spectra often appearing between $0.1 \mathrm{~s}$ and $0.25 \mathrm{~s}$. In the dominant short-period band, the HAY site produced larger spectral accelerations and NAE site appeared to give smaller spectral accelerations than the reference INS site. A spectral ratio of up to 3 with respect to INS may be obtained within Zone 1 reflecting possible topographical effects and the presence of shallow terrace remnants in this zone.

3. The transfer function analyses performed for the soil sites gave evidence that the thickness of the soil overlying the bedrock and the position in the valley plays a major role in determining the site characteristics. For a shallow site located adjacent to the edge of the valley, the predominant periods fall in the short-period range, while for deep sediment sites near the centre of the valley the dominant amplification peak tends to be at longer period. There was no instrument located on the valley floor between Taita gorge and central Hutt, so it was not possible to determine how the strong-motion response varies as the depth of sediment decreases in northern Lower Hutt. However, it is speculated that the influence of thickness of soil layer is a significant factor not only in the cross-valley direction but also in the along-valley direction, as shown in the microearthquake results of Taber \& Smith [13].

4. Of the four soil sites examined in the WRC study, PEL is identified as a resonant short-period site which produces stronger amplification in the along-valley direction than in the cross-valley direction. An average 5\% damped acceleration response spectral ratio of 4.1 at $0.35 \mathrm{~s}$ was calculated from ten events for the along-valley component. Individual events generally gave maximum spectral ratios of 6 or below, with one event producing an amplification of 10. The ELS site produced peaks in the same shortperiod band as PEL as well as broad-band amplification above $0.5 \mathrm{~s}$. Response spectral ratios of up to 6.6 for the short-period response and up to 7.2 (maximum around $1 \mathrm{~s}$ period) for the broad-band, longer-period amplifications were noted for particular events. GMT showed deamplifications in the short-period band up to about $0.25 \mathrm{~s}$ and strong broad-band amplifications above $0.4 \mathrm{~s}$, with prominent peaks appearing at periods as long as $1.5 \mathrm{~s}$ to $2.0 \mathrm{~s}$. A maximum amplification of 10 at $0.95 \mathrm{~s}$ has been noted for this site. The ground motion records at NZGS showed the possibility of strong amplifications over an even wider period band than at GMT, from below $0.25 \mathrm{~s}$ to 2.0 $s$ or greater, with prominent spectral amplification peaks appearing around $1.3 \mathrm{~s}, 1.5 \mathrm{~s}$ and sometimes at short periods less than about $0.5 \mathrm{~s}$. Maximum amplifications of about 5 for several events and exceeding 10 for one event were obtained.

NZGS was placed in the zone of strongest amplification principally because of possible strong amplification of longperiod motions, of which there have only been indications in the records to date, but which may be very important in its response to large magnitude shallow events. This longperiod amplification at NZGS is likely to be related as much to the great overall depth $(275 \mathrm{~m})$ of sediment as to the behaviour of the upper $10 \mathrm{~m}$ or so of material which determines the shorter-period response.

5. Of the three newly instrumented soil sites, NAES and WAI, as concluded by Taber \& Smith [13], are likely to produce the greatest amplifications in the Hutt Valley. In the accelerograph records, the NAES site showed prominent peaks around $0.2 \mathrm{~s}, 0.45 \mathrm{~s}$, and $0.7 \mathrm{~s}$ to $1.2 \mathrm{~s}$, with maximum amplifications exceeding 10 occurring in the period band of $0.7 \mathrm{~s}$ to $1.2 \mathrm{~s}$. The WAI site also produced amplifications exceeding 10 with a dominant peak at $1.2 \mathrm{~s}$. A prominent short-period peak identified for this site in the microearthquake study did not come through strongly in the events analyzed herein. The site on the reclamation land, CFT, showed similar response to ELS located in the same zone, with broad-band amplifications including peaks in the short-period range. A maximum spectral amplification of up to 10 was obtained for CFT at periods in excess of 1.0 s.

All of the strong-motion records analyzed in this paper had low levels of accelerations of up to about $10 \% \mathrm{~g}$ and hence the transfer function analyses were carried out under the assumption that soil responded linearly. Ground motions with larger peak ground accelerations will take the soil into the non-linear range and part of the energy will be dissipated by hysteretic action of the soil. This will reduce the amplifications of the soil sites. Depending on the soil type, the flexibility of the soil may increase with increasing strain in the soil, and this will essentially lengthen the fundamental period of the site as well as increase the damping.

Significant microzone effects observed in the Hutt Valley area are expected to show up strongly in an event of large magnitude centred tens of kilometres away from the Hutt Valley. Typically, a shallow earthquake of magnitude exceeding 7 at a distance of $100 \mathrm{~km}$ will lead, for buildings of similar fundamental periods, to similarities in the structural damage within defined microzone boundaries and variations in the extent of damage between different microzones. This type of earthquake is likely to be of sufficient duration and contain sufficient long-period energy to allow strong long-period response to develop at the deeper sites. The shallow focal depth may promote the excitation of strong surface wave effects. The peak ground acceleration of such an event with magnitude 7 may be expected to reach up to $20 \% \mathrm{~g}$ at soil sites, although more typically around $10 \% \mathrm{~g}$. Except possibly at soft cohesionless soil sites, acceleration of this order may not induce any significant non-linear responses at soil sites and hence the spectral amplifications estimated for these sites from weak to moderate amplitude motions recorded to date should not be reduced to any great extent.

Another possibility is a large event centred on a local active fault, such as from rupture of the Wellington fault through the Hutt Valley. This event should produce strong responses at all 
sites in the Hutt Valley, with variation in the ground motion between the sites probably being less pronounced than for the low to moderate amplitude motions described in this paper. Considerable reduction in the spectral amplifications compared to those in smaller amplitude motions may be expected, especially in the short-period ranges. However, variations in damage levels in different zones may again exist. Regardless of whether pronounced microzoning effects occur in the large magnitude Wellington fault event, it is emphasized that microzoning is important for the Hutt Valley because the probability of it experiencing shaking from a shallow, distant, large magnitude event is higher than that for an event occurring on the Wellington fault.

From the design perspective, it is important to note the different characteristics exhibited by various sites located within a few kilometres of each other. For example, for design purposes at a site with amplification over a broad period band, it may be appropriate to use an acceleration response spectrum which gives a nearly constant ratio to the rock spectrum in the broadband period range concerned. However, for a site exhibiting resonant amplification, the dominant peak often appears in a narrow period band and a site-specific peak needs to be considered when establishing design spectra. An investigation of the possible influence of response of the valley as a whole superimposed on more localised responses of the individual sites was beyond the scope of our study; however, significant superposition effects of this nature are plausible in the Hutt Valley. As such effects cannot be modelled in one-dimension, it is suggested that one-dimensional modelling for a site from the Hutt Valley area should be considered cautiously, particularly for sites near the edge of the valley. Long-period amplification probably depends on the overall geometry of the valley, and the total depth of sediments.

Although not studied here, it should be noted that surface waves are also likely to be significant factors for defining the response characteristics in the Hutt Valley. If surface waves are trapped within the valley boundaries, as in Mexico City in 1985, the duration of shaking will increase considerably on the valley floor because of the slowly decaying amplitude of surface waves as they reflect backwards and forwards across the valley. Surface waves contain low-frequency motions which may also excite the valley modes as a whole unit. Analytical modelling of the valley as a whole is needed to evaluate such problems.

\section{ACKNOWLEDGEMENTS}

The authors would like to thank Dick Hefford for his invaluable contribution to the maintenance of the accelerograph array in the Hutt Valley over a period of 20 years, Shirley O'Kane and David Baguley for their support in maintaining the array in recent years, Jim Cousins for processing the most of the records discussed in this paper, and Nick Perrin for providing the descriptions of the soil conditions at the accelerograph sites. We also thank John Taber and our institute colleagues for the interesting discussions leading to the selection of appropriate microzone boundaries and specification of their response characteristics for the Hutt Valley. We gratefully acknowledge the financial support provided by the EQC for upgrading mechanical-optical accelerographs to digital accelerographs and by the WRC for studying the microzone effects in the Hutt Valley. Finally, we thank David Dowrick, Russ Van Dissen, Jim Cousins, Nick Perrin, Bill Stephenson and Euan Smith for their constructive in-house reviews.

\section{REFERENCES}

1. Cousins, W.J., Hefford, R.T., McVerry, G.H., O'Kane, S.M., Baguley, D.E. 1991, "Computer Analyses of New Zealand Earthquake Accelerograms, Vol 6, Records from the Weber Earthquake of 13 May 1990", DSIR Physical Sciences, New Zealand.

2. Dellow, G.D., Read, S.A.L., Begg, J.G., Van Dissen, R.J., Perrin, N.D. 1992, "Distribution of Geological Materials in Lower Hutt, and Porirua, New Zealand: a component of a ground shaking hazard assessment", Bulletin of the New Zealand National Society for Earthquake Engineering, (this volume).

3. Katayama, T. 1982, "An Engineering Prediction Model of Acceleration Response Spectra and its Application to Seismic Hazard Mapping", Earthquake Engineering and Structural Dynamics, Vol 10, 149-163.

4. Matuschka, T., Berryman, K.R., O'Leary, A.J., McVerry, G.H., Mulholland, W.M., Skinner, R.I. 1985, "New Zealand Seismic Hazard Analysis", Bulletin of the New Zealand National Society for Earthquake Engineering, Vol $18,313-322$

5. McVerry, G.H., Sritharan, S. 1991, "Earthquake Site Response Effects Demonstrated by New Zealand StrongMotion Records", Proceedings of the Pacific Conference for Earthquake Engineering, Auckland, New Zealand, Vol 3, 205-216.

6. Perrin, N., personal communications

7. Sritharan, S., McVerry, G.H. 1991, "Quantifying Microzone Effects in the Hutt Valley using Strong-Motion Earthquake Records", DSIR Physical Sciences, (report prepared for Wellington Regional Council).

8. Sritharan, S., McVerry, G.H. 1990, "Analysis of StrongMotion Earthquake Records for Microzoning Central Wellington", Physics and Engineering Laboratory, DSIR, (report prepared for Wellington Regional Council).

9. Standards Association of New Zealand 1989, "Second Draft Code of Practice for General Structural Design and Design Loadings for Buildings (DZ4203)", Wellington, New Zealand.

10. Stephenson, W.R., Barker, P.R. 1992, "Evaluation of Sediment Properties in the Lower Hutt and Porirua Areas by Means of Cone and Seismic Cone Penetration Tests", Bulletin of the New Zealand National Society for Earthquake Engineering, (this volume).

11. Stephenson, W.R. 1989, "Normal Modes of a 'Cylindrical Valley' of Alluvium", Bulletin of the New Zealand National Society for Earthquake Engineering, Vol 22, 7680.

12. Stephenson, W.R. 1989, "Observation of a Directed Resonance in Soil Driven by Transverse Rock Motion", Bulletin of the New Zealand National Society for Earthquake Engineering, Vol 22, 81-89. 
13. Taber, J.J., Smith, G.C. 1992, "Frequency Dependent Amplification of Weak Ground Motions in Porirua and Lower Hutt, New Zealand", Bulletin of the New Zealand National Society for Earthquake Engineering, (this volume).

14. Van Dissen, R.J., Taber, J.J., Stephenson, W.R., Sritharan, S., Read, S.A.L., McVerry, G.H., Dellow, G.D., Barker, P.R. 1992, "Earthquake Ground Shaking Hazard Assessment for the Lower Hutt Area and Porirua Areas, New Zealand", Bulletin of the New Zealand National Society for Earthquake Engineering, (this volume). 